\title{
Fertility, Mortality and Age Composition Effects of Population Transition in China and India: 1950-2015
}

\author{
Aalok Ranjan Chaurasia
}

\begin{abstract}
This paper compares the population transition in China and India during 1950-2015 by decomposing population growth into the growth attributed to the changes in fertility and mortality (intrinsic growth), and the growth attributed to the change in population age composition (momentum growth). The analysis reveals similarities and differences in the population transition path followed by the two countries and suggests that India lags behind China by about 30 years in terms of population transition. The population transition in China has been rapid and inconsistent, while India's population transition has been slow and consistent. The momentum for growth intrinsic to respective populations has been the main contributor to population growth in both countries. The demographic dividend resulting from population transition in India has been substantially smaller than that in China because of differences in population transition paths. Unlike in China, population transition appears to have contributed only marginally to economic growth in India. This paper emphasises the importance of focussing population policy on the relative contribution of different demographic drivers to population growth.
\end{abstract}

Keywords: Population transition · China - India · Demographic dividend · Fertility · Mortality $\cdot$ Age composition

\section{Introduction}

China and India together account for almost 37 percent of the world population (United Nations 2015a). The two countries have also accounted for 37 percent of the world population growth between 1950 and 2015. Population transition in the two countries has, however, been different. China's population transition is nearing completion, with an average annual population growth rate of around 0.52 percent per year during 2010-15; a total fertility rate of 1.55; and an expectation of life at 
birth of more than 75 years. India's population, on the other hand, is still in the middle of the transition, with average annual population growth rate hovering around 1.3 percent per year; the total fertility rate remaining well above the replacement level; and an expectation of life at birth of less than 68 years. Between 2010 and 2015, more than 80 million people were added to India's population, compared to only 35 million in China. India's population is likely to surpass that of China by 2022 according to the medium variant of the 2015 revision of UN population projections (United Nations 2015a). The 2017 revision of UN population projections, however, suggests that India's population will surpass China's population in 2024 (United Nations 2017).

It is well known that population transition has important implications for economic growth. The decrease in fertility and the associated decrease in the dependency ratio, in turn lead to an increase in the share of the population concentrated in the working ages and hence in the ratio of the working age to the non-working age population (Bloom/Williamson 1998; Bloom/Canning 2004, 2005; Bloom et al. 2003; Bloom et al. 2000; Cai/Wang 2005; Mason 2007). The increased concentration of the population in the working ages suggests that even if there is no change in the output per worker, labour force participation rates, and unemployment rates, an increase in the share of the working age population will lead to an increase in the output per capita attributed purely to demographic changes - hence the name "demographic dividend". The impact of population transition on economic growth is, however, policy dependent (Mason 2007). A growth strategy that can facilitate creation of additional jobs to productively utilise the rapidly growing work force is necessary to benefit economically from demographic changes; otherwise, the demographic dividend cannot accelerate economic growth.

The available evidence suggests that the demographic dividends resulting from population transition in China and India have been different. China's GDP per capita (PPP) quadrupled between 1982 and 2000 (Wang/Mason 2007), with the demographic dividend accelerating economic growth by 2.3 percent per year, on average (Vermeer 2006). However, Cai and Wang (2005) projected way back in 2005 that China's demographic dividend would come to an end in 2015. Similarly, Keck (2013) speculated that China's demographic dividend could end by 2015. Recently, Roubanis (2016) has observed that China's demographic dividend has come to end, an observation which is supported by the present analysis. Meanwhile, India's demographic dividend has never been large enough to have a noticeable impact on the economic growth (Chaurasia/Gulati 2008). It is argued that much of India's potential demographic dividend lies ahead (Golley/Tyers 2012). India's per capita income was 66 percent higher than that of China in 1980 but, by 2008, China's per capita income was twice that of India. This cross over has been attributed to the very different demographic trajectories followed by the two countries (Bloom 2011). China's rapid population transition may, however, pose many future development challenges that may not be experienced by India. China will have far less time to prepare its social and economic infrastructure to deal with the effects of the rapid ageing of its population resulting from swift population transition (Wang 2010). Population ageing will proceed at a much slower rate in India, and population growth will continue for a 
longer period. It is expected that future population dynamics will have a positive effect on economic growth in India, but a negative effect in China (Choudhry/Elhorst 2010). It has also been emphasised that the demographic dividend will offer the single biggest hope for India to catch up with China in the coming years (Kelkar 2004).

In this paper, we present a comparative perspective of population transition in China and India during the 65 years from 1950 to 2015. The objective of the analysis is to identify distinctive features of the population transition path followed by the world's two most populous countries. More specifically, we analyse how fertility and mortality transition and the associated changes in the population age composition have contributed to the change in the population stock - the size and age composition - of the two countries. There are many studies that have carried out comparative analyses of population dynamics of China and India in different contexts, including economic growth (Bloom et al. 2006; Da Vanzo et al. 2011; Bloom 2011; Golley/Tyers 2012); migration (White/Subedi 2008); savings and economic growth (Joe et al. 2015), macroeconomics (Wolf et al. 2011), political economy (Desai 2003), and competitiveness (Schmidt 2011). However, there are few studies that have carried out a comparative analysis of the population dynamics of the two countries in the context of population transition - transition in fertility and mortality, and transition in population age composition (Coale 1983; Roy 1993; Adlakha/Banister 1995).

This paper is organised as follows. The next section of the paper outlines the methodology. Section three describes the data source. We have used the 2015 revision of population estimates prepared by the United Nations Population Division along with estimates of total fertility rate, expectation of life at births and estimates of net migration. Section four presents an outline of population growth in China and India from 1950 to 2015 . Section five decomposes the change in the natural population growth rate into the change attributed to fertility, mortality and population age composition. Section six decomposes population growth in the two countries into the growth attributed to fertility, mortality, age composition and population size. Transition in the age composition of the population is analysed in section seven of the paper. Findings of the analyses are discussed in a further section of the paper to highlight how population transition differed in the two countries. The last section discusses the lessons learnt from the population transition in the two countries and their policy implications.

The analysis of the key drivers of population growth has always been an area of interest to demographers. A number of studies have analysed future population growth under a set of assumptions about future trends in factors that affect population growth (Andreev et al. 2013; Bongaarts 2009, 1994; Bongaarts/Bulatao 1999; Frejka 1973, 1981). For example, Andreev, Kantorová and Bongaarts (2013) have compared four variants of population projections to estimate how future changes in different components of population growth will influence the future growth of the world population. Such analyses can inform policies and programmes aimed at balancing impending demographic changes and social, economic, health and environmental objectives (Bongaarts 1994; Bongaarts/Bulatao 1999). Notestein (1960) has used this approach to explore how changes in different factors affecting popu- 
lation growth were related to the change in the US population stock between 1930 and 1955.

There are also studies that have analysed demographic factors responsible for past changes in the population stock (Smith/Ahmed 1990; Horiuchi 1992, 1993; Kandiah/Horiuchi 1995). Horiuchi $(1992,1993)$ has analysed the stagnation in the decline of the world population growth rate during the 1980s, and Kandiah and Horiuchi (1995) have analysed trends and prospects of world population growth. They identified three main factors for stagnation: age structure, fertility trends in China and India, and the fact that in many developing countries, the decrease in fertility slowed down during the 1980s compared to the 1960s and 1970s. Alternatively, population growth can also be considered as the sum of the increase in population of different ages (Horiuchi 1995). This approach reflects the cohort replacement view of population growth, as opposed to the entrance-exit view of population growth according to which population is a group of individuals with two entry points (birth and immigration) and two exit points (death and emigration). Horiuchi (1995) has used this approach to analyse the determinants of the change in population growth rates in Sweden. He has shown that the growth rate of the population is a weighted sum of past changes attributed to the change in population size, age distribution, fertility, mortality, and migration. Horiuchi calls this decomposition the "retrospective decomposition" of growth rate, distinguishing it from the synchronous decomposition based on the growth balance equation of relative population change. The difference between the two is rooted in the period versus cohort approach of demographic analysis.

A consistent theme in research on population transition is related to the change in the population stock as population moves from the pre- to the post-transition phase. A synthetic index that reflects the change in population size during transition is the transition multiplier, which is the number by which population is multiplied when it moves from the pre- to the post-transition phase (Chesnais 1979, 1986). The population multiplier can be calculated theoretically as well as empirically. The theoretical approach involves approximation either through an analytical model (Keyfitz 1971) or by numerical simulation (Frejka 1973). The empirical approach involves an examination of historical evidence complemented by long range population projections (Chesnais 1990). On the other hand, the change in population age composition during transition is measured in terms of the change in the dependency ratio or, equivalently, the potential support ratio. The dependency ratio is defined as the ratio of children (0-14 years) and old persons (65 years and above) to the working age population (15-64 years), while the potential support ratio is reciprocal to the dependency ratio. Population transition has three phases with specific characteristics of population age composition. At the early stage of transition, the dependency ratio is high or the potential support ratio is low because of a high proportion of the young population. At the middle stage of the transition, the dependency ratio decreases or the potential support ratio increases. At the late stage of transition, the dependency ratio is again high or the potential support ratio is low because of a high proportion of the old population (Williamson 1977). During the period when the de- 
pendency ratio decreases or the potential support ratio increases, the demographic benefits (window of opportunity) can be reaped to accelerate economic growth.

\section{Methodology}

"Population transition" refers to the change in population stock, i.e. the size and age composition of the population (Schoen 2002). A live birth results in an increase in the population, while a death results in a decrease. A birth always increases the population at age zero, while death can occur at any age. Therefore, changes in the size of the population are always associated with changes in its age composition. The population may also decrease or increase, and its age composition may change because of migration - if a member of the population leaves it, population decreases and if a person from outside enters the population, the population increases. If $P(0)$ denotes the population at time $0 ; \mathrm{B}(0, \mathrm{t})$ denotes the number of live births during the time interval $(0, t) ; D(0, t)$ denotes the number of deaths; $I(0, t)$ denotes the number of in-migrants; and $\mathrm{O}(0, \mathrm{t})$ denotes the number of out-migrants, then the population at time $t, P(t)$ can be obtained from the simple identity known as the balancing equation of population change (Preston et al. 2001: 2).

$$
P(t)=P(0)+B(0, t)-D(0, t)+I(0, t)-O(0, t)
$$

If inward and outward movement of individuals is ignored, then the change in the size of the population during a given period depends upon the number of births and deaths during that period so that

$$
P(t)-P(0)=B(0, t)-D(0, t)
$$

Dividing both sides of equation (2) by the person-years lived during the interval $(0, t), P Y(0, t)$, we get

$$
r=b-d
$$

where $r$ is termed as the (crude) rate of natural increase (Preston et al. 2001: 8) or the natural population growth rate, $b$ is the (crude) birth rate and $d$ is the (crude) death rate. Thus, there are four factors in the absence of migration that determine the change in the population stock: 1) initial population size; 2) birth rate; 3) death rate; and 4) the period during which given birth and death rates apply (Vallin 2006). It is obvious that when $r=0$, size of the population stock remains unchanged; when $r>0$, population stock increases; and when $r<0$, population stock decreases. The larger the magnitude of $r$, the larger the change in the population stock. In this way, $r$ serves as a useful indicator of population transition. Demographic transition theory (Notestein 1945) says that as population moves from the pre-transition phase characterised by a high birth rate and a high death rate - to the post-transition phase - characterised by a low birth rate and a low death rate - the size of the population 
increases, and its age composition changes. The reason is that there is a time gap between the onset of the decrease in the death rate and the onset of the decrease in the birth rate, so that $r$ first increases and then decreases.

The primary determinant of the birth rate is the actual birth performance or fertility of individual woman. However, not all women are biologically capable of giving birth. Most of the births are confined to women aged 15-49 years which is also known as the reproductive age group. Moreover, the probability of conception also varies by age. In other words, the birth rate has two components, one age independent and the other influenced by population age composition. If $f$ denotes the birth rate independent of age, then we can state that

$$
b=f \times(b / f)=f \times a b
$$

where $a b=b / f$ is a multiplier which reflects the effect of age composition on the birth rate. Similarly, the death rate also has two components. If / denotes the age independent death rate, then, we can state that

$$
d=I \times(d / /)=I \times a d
$$

Equation (3) may now be written as

$$
r=f \times a b-I \times a d
$$

Following Kitagawa (1955), $r$ can be decomposed into two components as follows

$$
r=(f-l) \times(a b+a d) / 2+((f+/) \times(a b-a d) / 2=i+a
$$

The first component on the right of equation (6) is the intrinsic component which is determined by the prevailing regimes of fertility and mortality as measured by the age independent birth rate, $f$, and the age independent death rate, $l$, and may be termed as the intrinsic rate of population growth (Espenshade 1975). The second component is the age component, $a$, which reflects the age composition effects on the birth rate, $a b$, and the age composition effects on the death rate, $a d$, and hence on $r$. It is obvious from equation (6) that $r$ will not be zero, even if $f=/$ or when $i=0$. The change (increase or decrease) in the population stock therefore depends not only on the change in fertility and mortality, but also on the change in population age composition. The age component of the natural population growth rate is closely related to the concept of population momentum (Keyfitz 1971; Schoen/ Kim 1991) which, in its narrowest formulation, refers to the fact that a population closed to migration may continue to increase even when fertility decreases to the replacement level (Preston et al. 2001: 136). Population momentum measures the cumulative contribution of age composition to population change in all future years after fertility has been set at the replacement level. It is usually measured in relative terms as the ratio of the size of the longrun stationary population to that of the ob- 
served population when replacement fertility is first attained (Espenshade/Tannen 2015 ) and can be both greater than or less than the limiting value of 1 . When the age composition of the population is younger than the age composition of the stationary population, the momentum factor exceeds 1 . In this case, population continues to increase even after the replacement fertility is reached. If the age composition of the population is older than that of the stationary population, the momentum factor is less than 1. In this case, population decreases after the replacement fertility is reached. When the population age composition is the same as that of the stationary population, the momentum factor is 1 . In this case, the natural population growth rate is determined solely by the intrinsic population growth rate (Preston/ Guillot 1997). It is however clear from equation (6) that the concept of momentum is not confined to reaching the replacement fertility only. It applies to any change in the population stock. When the population is closed with respect to migration, the change in the population stock depends upon the change in fertility and mortality and change in the population age composition, which is the legacy of past fertility and mortality dynamics (Preston et al. 2001: 136). When the population is open for migration, both the size and the age composition of net migrant population also contributes to momentum growth (Espenshade/Tannen 2015).

Equation (6) suggests that the change in the natural population growth rate, $r$, should be analysed in terms of the change in the age independent birth rate, $f$, age independent death rate, $I$, age composition effects on the birth rate, $a b$, and age composition effects on the death rate, ad. Now

$$
\Delta r=r_{2}-r_{1}=\left(b_{2}-d_{2}\right)-\left(b_{1}-d_{1}\right)=\left(b_{2}-b_{1}\right)+\left(d_{2}-d_{1}\right)=\Delta b-\Delta d
$$

and

$$
\begin{aligned}
\Delta b=\left(b_{2}-b_{1}\right) & =f_{2} \times a b_{2}-f_{1} \times a b_{1} \\
& =\left[\left(f_{2}-f_{1}\right) \times\left(a b_{1}+a b_{2}\right) / 2\right]+\left[\left(a b_{2}-a b_{1}\right) \times\left(f_{1}+f_{2}\right) / 2\right] \\
& =\partial_{f}+\partial_{a b}
\end{aligned}
$$

Similarly,

$$
\begin{aligned}
\Delta d=\left(d_{2}-d_{1}\right) & =I_{2} \times a d_{2}-I_{1} \times a d_{1} \\
& =\left[\left(I_{2}-I_{1}\right) \times\left(a d_{1}+a d_{2}\right) / 2\right]+\left[\left(a d_{2}-a d_{1}\right) \times\left(I_{1}+I_{2}\right) / 2\right] \\
& =\partial_{1}+\partial_{a d}
\end{aligned}
$$

Substituting from (8) and (9) in (7), we get

$$
\begin{aligned}
\Delta r & =\left(\partial_{f}+\partial_{a b}\right)-\left(\partial_{l}+\partial_{a d}\right) \\
& =\left(\partial_{f}-\partial_{l}\right)+\left(\partial_{a b}-\partial_{a d}\right) \\
& =\Delta_{i}+\Delta_{a}
\end{aligned}
$$

The first term on the right of equation (10) is determined by the change in the age independent birth rate, $f$, and the age independent death rate, $I$, or the change 
in the intrinsic rate of population growth while the second term is determined by the change in the age composition of the population as it affects the birth rate and the death rate. It also follows from equation (10) that $\Delta r$ will not be zero but will be equal to $\Delta_{a}$ even when there is no change in fertility and mortality so that $\Delta_{i}=0$. Equation (10) takes into account both the change in the intrinsic rate of population growth and the change in the population age composition in explaining the change in the population stock. It addresses the controversial issue of which demographic indicators are more efficient in analysing population transition. In the absence of migration, the logical choice of the indicator reflecting population transition is the natural population growth rate, i.e. the difference between the birth rate and the death rate. However, both birth rate and death rate are crude measures respectively of fertility and mortality which are affected - in addition to the level of fertility and mortality - by the population age and sex composition. Using only crude rates to measure population transition, therefore, may obscure the change in fertility and mortality. Birth and death rates may stay at a relatively high level despite low levels of fertility and mortality because population age composition contributes to keeping them high. On the other hand, fertility and mortality indicators such as the total fertility rate and the expectation of life at birth have limitations in analysing population transition. First, both indicators are based on a hypothetical rather than the actual population. Second, changes in the total fertility rate and in the expectation of life at birth do not necessarily lead to change, respectively, in the birth rate and the death rate and hence in the natural population growth rate because birth rate and death rate are also influenced by changes in population age and sex composition. Analysis of population transition requires that changes in both fertility and mortality and changes in population age composition are taken into account. Equation (10) provides this analytical framework. It essentially weighs the differences in the levels of fertility and mortality by the average levels of the age structure effects on birth and death rates while the difference in the age structure effects on birth and death rates is weighed by average levels of fertility and mortality. There are other decompositional procedures also, but they introduce a residual or interaction term which is often difficult to interpret (Preston et al. 2001).

Decomposing the change in the natural population growth rate, $r$, into its components also has policy relevance. If the change in the age component accounts for, for example, 80 percent of the change in the natural population growth rate, then there is little relevance of policies and programmes directed towards reducing fertility and mortality in the context of population transition. In such a scenario, population policies and programmes should be directed towards addressing the age component of the natural population growth rate, which is the result of past fertility and mortality dynamics (Bongaarts 1994). For example, Bourgeois-Pichat and Taleb (1970) had demonstrated that the target set by Mexico to achieve a population growth rate of zero by 2000 was unrealistic because the age composition of the population of Mexico was conducive to positive population growth.

The application of equation (10) requires measurement of the age independent birth rate, $f$, and the age independent death rate, $I$. A measure of $f$ can be derived from the total fertility rate (TFR) which is actually the sum of the age-specific birth 
rates of reproductive-age (15-49 years) women. Dividing the total fertility rate (TFR) by 35 - the length of the reproductive period - gives the age independent birth rate per woman of reproductive age. Finally, multiplying the age independent birth rate per woman of reproductive age by the proportion of reproductive age women $(w)$ in the population gives an estimate of the age independent birth rate, $f$. Thus, the age independent birth rate, $f$, may be calculated from the total fertility rate as

$$
f=\mathrm{w} \times(\mathrm{TFR} / 35)
$$

It may be noticed that $f$ is actually a scalar multiple of the total fertility rate (TFR). Horiuchi (1991) has shown that the ratio of the birth rate to TFR is a measure of the age structure effects on the birth rate. As such, the ratio $b / f$ is also a measure of the age structure effects on the birth rate.

Similarly, the expectation of life at birth $\left(e_{0}\right)$ is a measure of mortality which depends only upon age-specific probabilities of death and is not influenced by the age composition of the population. The reciprocal of $e_{0}$, the life table death rate, may therefore be taken as a measure of the age independent death rate, / and the ratio $d / /$ may be argued to be a measure of the age composition effects on the death rate in the same manner as the ratio $b / f$ is a measure of the age composition effects on the birth rate. It may however be noticed that the interpretation of the ratio $d / /$ as a measure of the age composition effects on the death rate is not as straightforward as the interpretation of the ratio $b / f$ as a measure of the age composition effects on the birth rate (Horiuchi 1992), as it depends on the stage of mortality transition (United Nations 2006). At the early stage of transition, the decline in mortality is primarily confined to infancy and early childhood, which exerts an influence on population change similar to the increase in fertility. Therefore, initial stages of mortality transition tend to make the population as a whole younger, even as the probabilities of survival to middle and older ages increase. As the mortality transition advances, the decrease in mortality is increasingly confined to older ages, so that the late stage of mortality transition tends to make the population as a whole grow older by increasing the proportion of old persons in the population.

We have used two indicators to measure the change in the population age structure resulting from population transition: 1) the potential support ratio or the ratio of the working age population (15-64 years) to the non-working age population (0-14 years and 65 years and above); and 2) the difference between the growth rate of the working age population and the growth rate of the non-working age population in a given time period. These two indicators have been selected to capture the transition in the population age structure in place of the proportionate age distribution of the population. The reason is that the two indicators are also used to quantify the demographic dividend that is generated as the result of population transition and that has implications for economic growth. The demographic dividend is accrued in a given period when the growth rate of the working age population is relatively more rapid than the growth rate of the non-working age population, so that the difference between the two growth rates is positive. When the growth rate of the working age population is slower than the growth rate of the non-working age population, the 
difference between the two growth rates is negative and no demographic dividend is accrued. It is also obvious that the larger the difference between the two growth rates, the larger the demographic dividend generated as the result of population transition, and hence the larger the potential contribution of population transition to accelerating economic growth even if other determinants of economic growth remain unchanged.

\section{Data source}

The present analysis uses estimates of population and selected demographic indicators for China and India prepared by the United Nations Population Division in its 2015 revision for different quinquennial during the period 1950-2015 (Table 1). United Nations Population Division provides estimates of population after adjusting for net migration. At the same time, estimates of net migration in a quinquennial are also provided by the United Nations Population Division. Based on these two data, we have estimated population of the two countries which is not adjusted for net migration and these estimates are used in the present analysis. A comparison of the population estimates adjusted for net migration and not adjusted for net migration suggests that net migration accounts for only a small proportion of the population of the two countries. Between 1950 and 2015, around 11 million people in China and around 6 million people in India are estimated to have emigrated. The average annual birth rate, average annual death rate and the average annual natural population growth rate used in the present analysis have been calculated for different quinquennial based on the population estimates unadjusted for net migration.

We have chosen to use the UN population estimates rather than the official population estimates of the two countries for two reasons. First, estimates prepared by the United Nations Population Division are based on a set of uniform assumptions and estimation methodology. These estimates, therefore, permit inter-country comparison. Second, official population estimates for both countries are not available for various periods between 1950 and 2015. Therefore, comparing the transition paths followed by the two countries would require interpolation. There is however a possibility that the UN population estimates differ from official population estimates for the two countries.

\section{$4 \quad$ Population growth in China and India}

The UN Population Division estimates that China's population increased from 544 million in 1950 to 1376 million in 2015, while India's population increased from 376 to 1311 million (Table 1). If net migration is taken into account, China's population is estimated to have increased to 1387 million in 2015 compared to India's 1317 million (Fig. 1). Population increase in both countries has been associated with a decrease in fertility and mortality. The decrease in fertility in China has, however, not been consistent as TFR increased, rather than decreased, between 1955-60 and 1965- 
Tab. 1: Population, birth rate, death rate, total fertility rate and expectation of life at birth in China and India, 1950-2015

\begin{tabular}{|c|c|c|c|c|c|c|}
\hline \multirow[t]{2}{*}{ Year } & \multicolumn{2}{|c|}{ Population (million) } & \multirow{2}{*}{\multicolumn{2}{|c|}{$\begin{array}{c}\text { Birth Death } \\
\text { rate } \\
\text { per } 1,000 \text { inhabitants }\end{array}$}} & \multirow[t]{2}{*}{$\begin{array}{l}\text { Total fertility } \\
\text { rate }\end{array}$} & \multirow[t]{2}{*}{$\begin{array}{l}\text { Expectation of } \\
\text { life at birth } \\
\text { (years) }\end{array}$} \\
\hline & $\begin{array}{l}\text { Adjusted for } \\
\text { migration }\end{array}$ & $\begin{array}{l}\text { Not adjusted } \\
\text { for migration }\end{array}$ & & & & \\
\hline & \multicolumn{6}{|c|}{ China } \\
\hline 1950 & 544.113 & 544.113 & & & & \\
\hline 1955 & 598.574 & 598.740 & 42.242 & 23.101 & 6.107 & 43.389 \\
\hline 1960 & 644.450 & 644.624 & 36.491 & 21.719 & 5.476 & 44.041 \\
\hline 1965 & 706.591 & 707.824 & 39.740 & 21.027 & 6.150 & 44.125 \\
\hline 1970 & 808.511 & 809.756 & 39.930 & 13.002 & 6.300 & 55.051 \\
\hline 1975 & 905.580 & 907.939 & 32.157 & 9.256 & 4.850 & 61.320 \\
\hline 1980 & 977.837 & 980.624 & 22.564 & 7.157 & 3.014 & 65.192 \\
\hline 1985 & 1052.622 & 1055.667 & 21.342 & 6.591 & 2.520 & 67.446 \\
\hline 1990 & 1154.606 & 1157.805 & 25.153 & 6.675 & 2.750 & 68.630 \\
\hline 1995 & 1227.841 & 1231.864 & 18.955 & 6.553 & 2.000 & 69.386 \\
\hline 2000 & 1269.975 & 1274.504 & 13.244 & 6.438 & 1.480 & 70.587 \\
\hline 2005 & 1305.601 & 1312.275 & 12.059 & 6.218 & 1.500 & 72.852 \\
\hline 2010 & 1340.969 & 1349.845 & 12.084 & 6.438 & 1.530 & 74.438 \\
\hline \multirow[t]{2}{*}{2015} & 1376.049 & 1386.725 & 12.329 & 6.938 & 1.550 & 75.432 \\
\hline & \multicolumn{6}{|c|}{ India } \\
\hline 1950 & 376.325 & 376.325 & & & & \\
\hline 1955 & 409.280 & 409.386 & 43.629 & 26.783 & 5.903 & 36.622 \\
\hline 1960 & 449.662 & 449.772 & 42.657 & 23.834 & 5.896 & 39.658 \\
\hline 1965 & 497.920 & 498.115 & 41.530 & 21.103 & 5.891 & 42.733 \\
\hline 1970 & 553.943 & 554.384 & 39.885 & 18.469 & 5.723 & 46.026 \\
\hline 1975 & 621.704 & 620.026 & 38.522 & 16.130 & 5.411 & 49.399 \\
\hline 1980 & 697.230 & 694.420 & 36.784 & 14.109 & 4.975 & 52.557 \\
\hline 1985 & 782.085 & 778.792 & 35.691 & 12.745 & 4.683 & 54.947 \\
\hline 1990 & 870.602 & 867.263 & 33.155 & 11.625 & 4.266 & 56.746 \\
\hline 1995 & 960.875 & 958.214 & 30.163 & 10.209 & 3.833 & 59.202 \\
\hline 2000 & 1053.481 & 1051.537 & 27.696 & 9.102 & 3.483 & 61.588 \\
\hline 2005 & 1144.326 & 1144.589 & 25.365 & 8.401 & 3.141 & 63.569 \\
\hline 2010 & 1230.985 & 1234.077 & 22.923 & 7.864 & 2.797 & 65.463 \\
\hline 2015 & 1311.051 & 1316.741 & 20.354 & 7.384 & 2.480 & 67.473 \\
\hline
\end{tabular}

Source: United Nations (2015)

70 and again between 1980-85 and 1985-90. In India, fertility decrease has been consistent once it started decreasing after 1970. Fertility in India decreased even 
Fig. 1: Population growth in China and India, 1950-2015

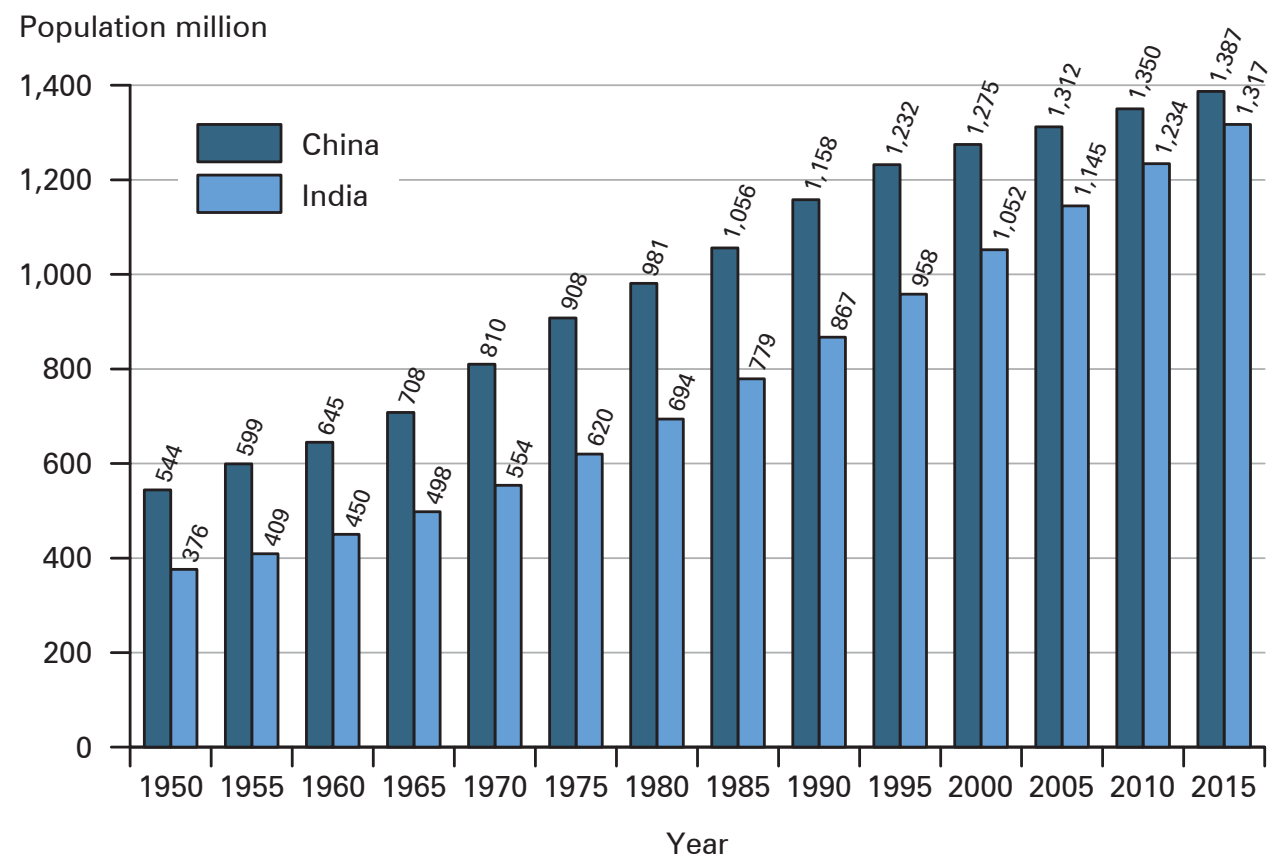

Source: own calculations based on estimates prepared by the United Nations (2015)

when there was a setback to India's official family planning programme after 1977, although there was some slowdown in the pace of decrease in fertility (Government of India 2013). Mortality also decreased in both countries, but the decrease has again been faster in China than in India. Most of the decrease in mortality in China was confined between 1965 and 1975. In India, mortality decrease has been slow and the pace of decrease appears to have slowed down after 1980 (Chaurasia 2010).

In both countries, the average annual natural population growth rate was the highest during 1965-70 (Table 2; Fig. 2). After 1965-70, the natural population growth rate decreased very sharply in China, although the trend reversed during 1985-90. The rate decreased slowly in India, so that the gap between the two countries widened until 1995-2000. The natural population growth rate in China was consistently lower than that in India, except during 1950-55 and 1965-75. The faster decrease in the natural population growth rate in China has been due to faster decrease in both fertility and mortality. The intrinsic population growth rate in China turned negative after 1995, but it has always been positive in India. The age component of the natural population growth rate, on the other hand, always contributed to increasing the natural population growth rate in both countries. The contribution of the age component increased in both countries, up to 1985-90 in China and up to 1990-95 in India and decreased thereafter, although the decrease has been very slow in India. In both countries, the relative contribution of the intrinsic and the age components of the natural population growth rate reversed over time. In China, the positive natu- 
Tab. 2: Natural population growth rate $(r)$; age independent birth rate $(f)$; age independent death rate (I); age structure effects on birth rate $(a b)$ and death rate $(\mathrm{ad})$ in China and India: 1950-2015

\begin{tabular}{|c|c|c|c|c|c|c|c|}
\hline \multirow[t]{3}{*}{$\begin{array}{l}\text { Period }^{*} \\
\text { (from ... } \\
\text { below ...) }\end{array}$} & \multirow[t]{2}{*}{$\begin{array}{c}\text { Natural } \\
\text { population } \\
\text { growth rate }\end{array}$} & \multicolumn{2}{|c|}{$\begin{array}{l}\text { Components of } \\
\text { natural population } \\
\text { growth rate }\end{array}$} & \multicolumn{2}{|c|}{ Age independent } & \multicolumn{2}{|c|}{$\begin{array}{l}\text { Age composition } \\
\text { effects on }\end{array}$} \\
\hline & & $\begin{array}{l}\text { Intrinsic } \\
\text { comp }\end{array}$ & $\begin{array}{l}\text { Age } \\
\text { nent }\end{array}$ & Birth & Death & Birth & \\
\hline & (r) & $\begin{array}{c}\text { (b) } \\
0 \text { inhabit }\end{array}$ & (d) & $\begin{array}{c}(f) \\
\text { per } 1,000\end{array}$ & per 1,000 inhabitants & $(a b)$ & $(a d)$ \\
\hline \multicolumn{8}{|c|}{ China } \\
\hline $1950-55$ & 19.141 & 17.840 & 1.301 & 40.490 & 23.047 & 1.043 & 1.002 \\
\hline $1955-60$ & 14.771 & 12.123 & 2.648 & 34.798 & 22.706 & 1.049 & 0.957 \\
\hline $1960-65$ & 18.712 & 15.363 & 3.350 & 38.295 & 22.663 & 1.038 & 0.928 \\
\hline $1965-70$ & 26.928 & 18.377 & 8.551 & 39.428 & 18.165 & 1.013 & 0.716 \\
\hline $1970-75$ & 22.901 & 11.670 & 11.232 & 30.785 & 16.308 & 1.045 & 0.568 \\
\hline $1975-80$ & 15.406 & 3.675 & 11.731 & 19.938 & 15.339 & 1.132 & 0.467 \\
\hline $1980-85$ & 14.751 & 2.615 & 12.136 & 18.040 & 14.827 & 1.183 & 0.445 \\
\hline $1985-90$ & 18.477 & 5.235 & 13.242 & 20.865 & 14.571 & 1.206 & 0.458 \\
\hline 1990-95 & 12.403 & 0.875 & 11.527 & 15.454 & 14.412 & 1.227 & 0.455 \\
\hline $1995-2000$ & 6.806 & 2.082 & 8.888 & 11.564 & 14.167 & 1.145 & 0.454 \\
\hline $2000-05$ & 5.841 & 1.303 & 7.144 & 11.945 & 13.726 & 1.010 & 0.453 \\
\hline $2005-10$ & 5.646 & 0.850 & 6.496 & 12.273 & 13.434 & 0.985 & 0.479 \\
\hline 2010-15 & 5.391 & 0.987 & 6.378 & 11.986 & 13.257 & 1.029 & 0.523 \\
\hline \multicolumn{8}{|c|}{ India } \\
\hline $1950-55$ & 16.846 & 13.800 & 3.046 & 40.761 & 27.306 & 1.070 & 0.981 \\
\hline $1955-60$ & 18.823 & 14.621 & 4.202 & 39.692 & 25.216 & 1.075 & 0.945 \\
\hline $1960-65$ & 20.427 & 14.975 & 5.452 & 38.530 & 23.401 & 1.078 & 0.902 \\
\hline $1965-70$ & 21.415 & 14.821 & 6.594 & 37.131 & 21.727 & 1.074 & 0.850 \\
\hline 1970-75 & 22.392 & 14.359 & 8.033 & 35.505 & 20.243 & 1.085 & 0.797 \\
\hline $1975-80$ & 22.675 & 13.045 & 9.630 & 33.111 & 19.027 & 1.111 & 0.742 \\
\hline 1980-85 & 22.946 & 12.151 & 10.795 & 31.440 & 18.199 & 1.135 & 0.700 \\
\hline $1985-90$ & 21.530 & 10.150 & 11.380 & 28.843 & 17.622 & 1.149 & 0.660 \\
\hline $1990-95$ & 19.954 & 8.232 & 11.722 & 26.290 & 16.891 & 1.147 & 0.604 \\
\hline $1995-2000$ & 18.594 & 6.944 & 11.650 & 24.435 & 16.237 & 1.133 & 0.561 \\
\hline $2000-05$ & 16.964 & 5.601 & 11.362 & 22.467 & 15.731 & 1.129 & 0.534 \\
\hline $2005-10$ & 15.059 & 4.072 & 10.987 & 20.215 & 15.276 & 1.134 & 0.515 \\
\hline $2010-15$ & 12.970 & 2.632 & 10.338 & 18.059 & 14.821 & 1.127 & 0.498 \\
\hline
\end{tabular}

* Note: The period 1950-55 refers to the years 1950 until 1954 and 1955-60 refers to the years 1955 until 1959 and so on: meaning the lower limit is always included and the upper limit is excluded.

Source: own calculations

ral population growth rate since 1995 has been due to its positive age component, whereas in India almost 80 percent of the natural population growth rate during 2010-15 is attributed to the age component. 
Fig. 2: Average annual natural population growth rate in China and India, 19502015

Natural population growth rate per 1,000 inhabitants

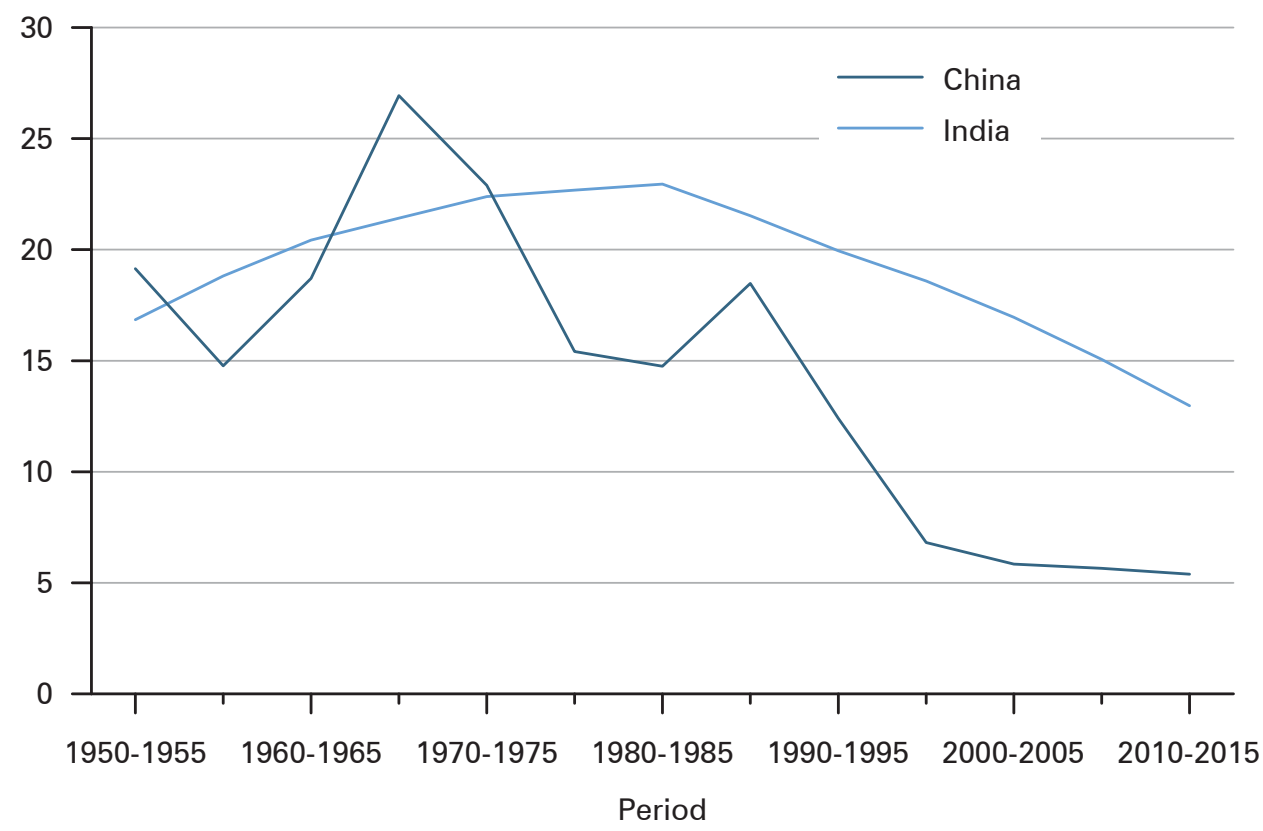

Source: own calculations

Table 2 shows that, in general, age composition effects have inflated the age independent birth rate, $f$, in both countries. The age composition induced inflation increased very rapidly in China between 1960-65 and 1990-95. For example, these effects inflated the age independent birth rate, $f$, by almost 23 percent in China during 1990-95. However, they decreased sharply after 1990-95, dipping below 1 during 2005-10, which implies that age composition deflated, rather than inflated the age independent birth rate, $f$. In India, the age composition induced inflation increased until 1985-90, when they inflated the age independent birth rate, $f$, by almost 15 percent. By contrast, the age composition effects deflated the age independent death rate, I, in both countries except in China during 1950-55. Thus, the age composition contributed to increasing the natural population growth rate in both countries with only two exceptions, both specific to China.

\section{Decomposition of the change in natural population growth rate}

The average annual natural population growth rate in China decreased by almost 72 percent between 1950-55 and 2010-2015, but by 23 percent in India over the same period (Table 3). The decrease in fertility induced a decrease of almost 164 percent in the natural population growth rate in China (Fig. 3) and around 151 percent in 







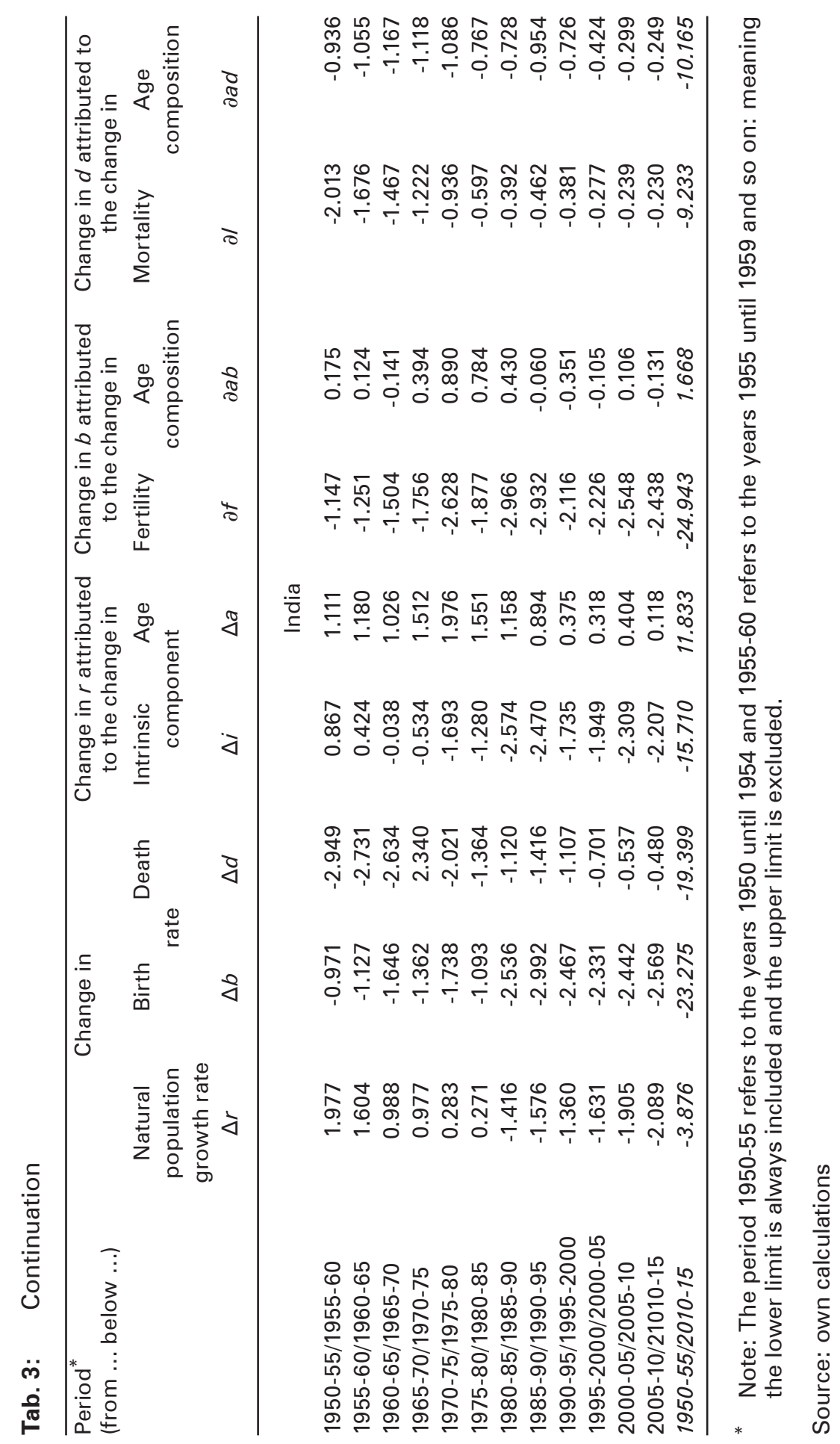


Fig. 3: Decomposition of natural population growth rate $(r)$ in China during 1950-2015 into growth rate attributed to fertility $\left(r_{-} f\right)$, mortality $\left(r_{-} /\right)$, age composition effects on birth rate $\left(r_{-} a b\right)$ and age composition effects on death rate $\left(r_{-} a d\right)$

Growth rate per 1,000 inhabitants



Source: own calculations

India (Fig. 4). The change in the age composition effects on the birth rate induced an increase of 8 percent in China and 13 percent in India. Similarly, the decrease in mortality and the change in the age composition effects on the death rate induced an increase of 35 percent and 49 percent, respectively, in China, and 59 percent and 56 percent, respectively, in India. In other words, the change in the intrinsic component induced a decrease of around 129 percent in the natural population growth rate in China and 92 percent in India, but the age component induced an increase of 57 percent in China and 69 percent in India.

In both countries, the change in the intrinsic component and the change in the age component of the natural population growth rate have tended to offset each other, with only a few exceptions. In China, the change in the two components contributed to increasing the natural population growth rate from 1955-60 to 1965-70 and again from 1980-85 to 1985-90. Similarly, change in both components contributed to decreasing the natural population growth rate from 1990-95 to 1995-2000 and again from 2005-10 to 2010-2015. In India, change in both components contributed to increasing the natural population growth rate from 1950-55 to 1960-65.

Table 3 explains why population transition reversed in China during 1955-70 and again during 1980-90. The reversal during 1955-60/1960-65 and during 1980- 
Fig. 4: Decomposition of natural population growth rate $(r)$ in India during 1950-2015 into growth rate attributed to fertility $\left(r_{-} f\right)$, mortality $\left(r_{-} /\right)$, age composition effects on birth rate $\left(r_{-} a b\right)$ and age composition effects on death rate $\left(r_{-} a d\right)$

Growth rate per 1,000 inhabitants

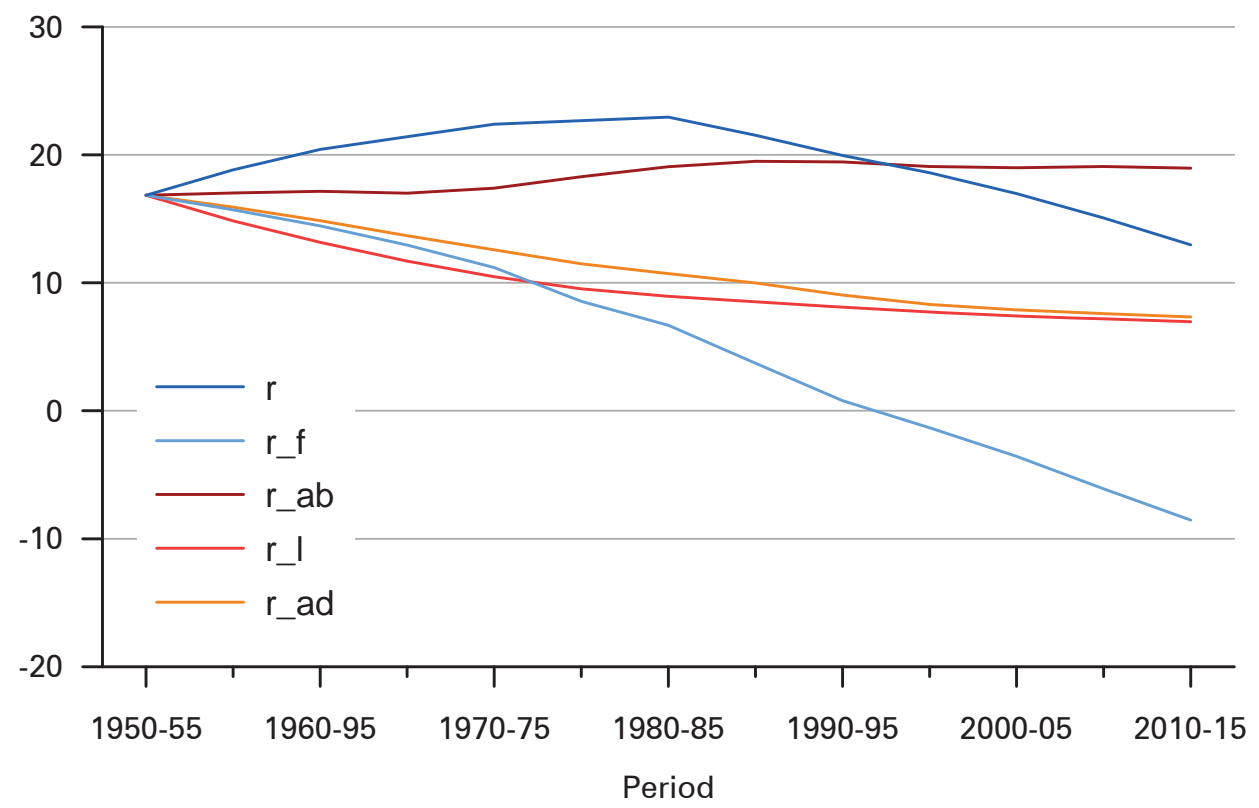

Source: own calculations

85/1985-90 was due to the increase in fertility, whereas the reversal during 1960$65 / 1965-70$ was primarily due to a very rapid decrease in mortality, although fertility also increased marginally during this period. In India, the natural population growth rate started decreasing only after 1985, but there has been no reversal, as the decrease in fertility has been large enough to compensate for the decrease in mortality and changes in the age structure effects on birth and death rates.

\section{Decomposition of the change in population size}

China's population increased by 55 million between 1950 and 1955. If this increase had remained constant in every quinquennial from 1950 to 2015, China's population would have increased by 710 million to reach 1254 million in 2015, as opposed to the actual count of 1387 million, or an additional increase of 133 million (Table 4). This additional increase is the result of a decrease of 1049 million due to the decrease in fertility; an increase of 79 million due to the change in the age composition effects on the birth rate; an increase of 239 million due to the decrease in mortality, an increase of 364 million due to the change in the age composition effects on the death 


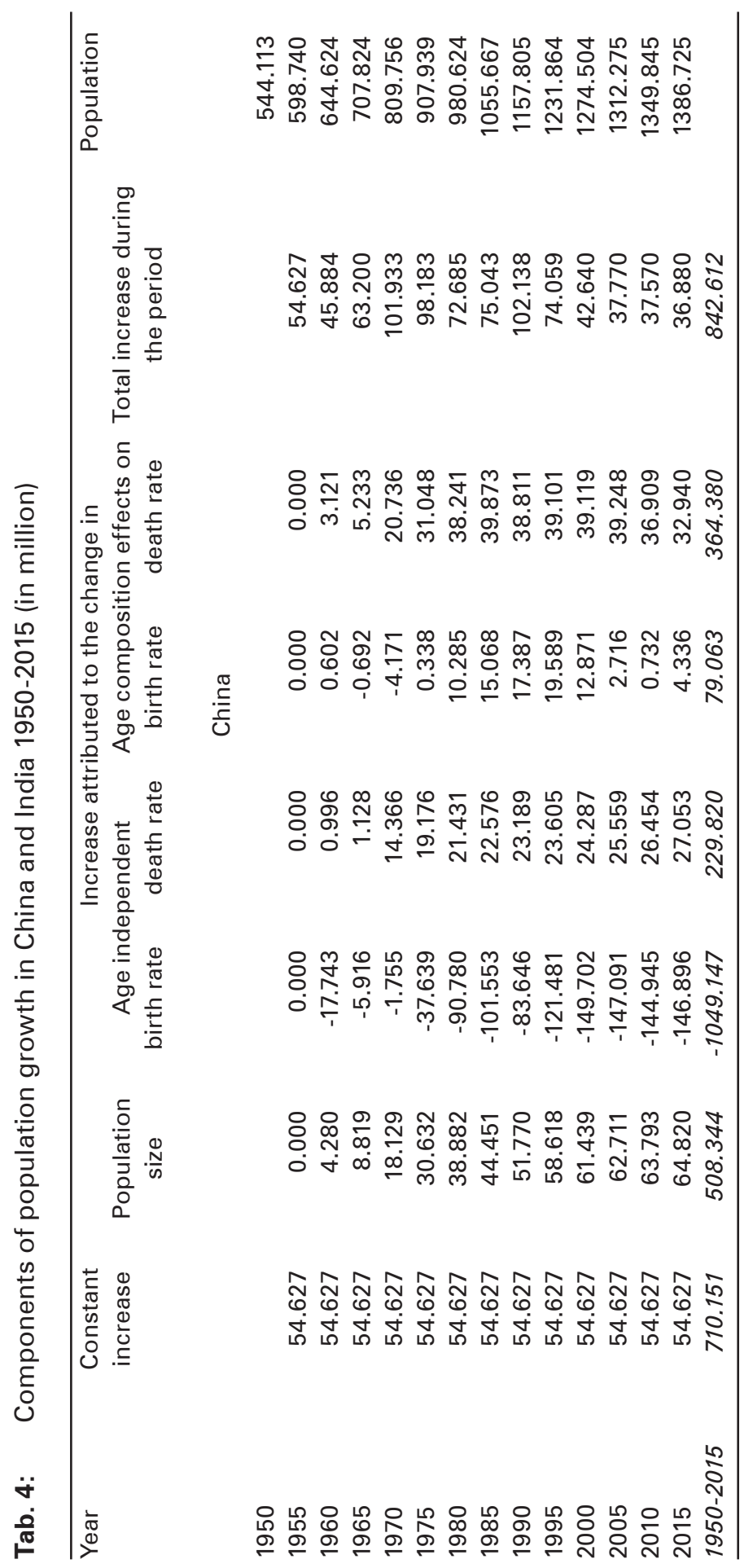




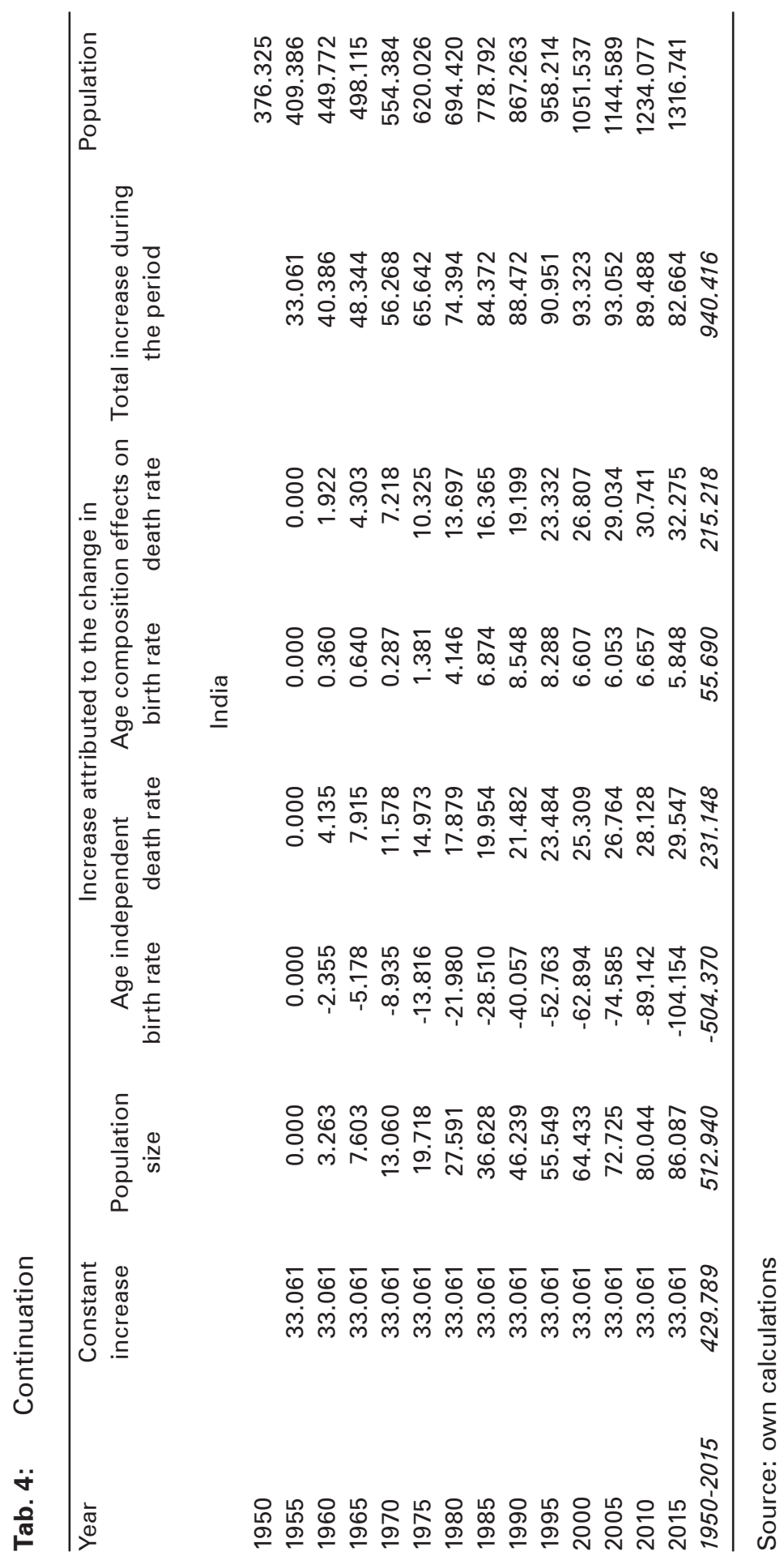


Fig. 5: Decomposition of population growth $(P)$ in China during 1950-2015 into growth attributed to different components of population growth

Population (million)



Note: $P_{-}$

Change attributed to change in fertility only

$\mathrm{P}^{-} \mathrm{f}+\mathrm{l}$

$P_{-} f+I+a b$

$P \_f+I+a b+a d$

$P_{-} f+I+a b+a d+s$
Change attributed to change in fertility and mortality

Change attributed to change in fertility, mortality and age composition effects on birth rate

Change attributed to change in fertility, mortality, age composition effects on birth rate and age composition effects on death rate

Change attributed to change in fertility, mortality, age composition effects on birth rate, change in age composition effects on death rate and population size

Source: own calculations

rate and an increase of 508 million due to the increase in population size (Fig. 5). In India, the net addition to the population between 1950 and 1955 was 36 million. At this constant increase, India's population would have increased by 430 million to reach 806 million in 2015, as opposed to the actual count of 1317 million, or an additional increase of 511 million. This additional increase is the result of a decrease of 504 million because of the decrease in fertility, an increase of 56 million due to the change in age composition effects on the birth rate, an increase of 231 million due to the decrease in mortality, an increase of 215 million due to the change in the age composition effects on the death rate and an increase of 513 million due to the 
Fig. 6: Decomposition of population growth $(P)$ in India during 1950-2015 into growth attributed to different components of population growth

Population (million)



Note: $P_{-} f$

$$
\begin{aligned}
& P_{-} f+l \\
& P_{-} f+l+a b \\
& P_{-} f+l+a b+a d
\end{aligned}
$$

Change attributed to change in fertility only

Change attributed to change in fertility and mortality

Change attributed to change in fertility, mortality and age composition effects on birth rate

Change attributed to change in fertility, mortality, age composition effects on birth rate and age composition effects on death rate

$P_{-} f+I+a b+a d+s \quad$ Change attributed to change in fertility, mortality, age composition effects on birth rate, change in age composition effects on death rate and population size

Source: own calculations

increase in population size (Fig. 6). Population increase due to the change in age composition and the increase in population size are essentially momentum effects. This means that momentum built in the population stock resulted in an increase of around 952 million in China's population and around 784 million in India's population, whereas the change in fertility and mortality accounted for a decrease of around 819 million in China's population and about 273 million in India's population. As the result, the actual increase in population in China was 133 million, while that in India was almost 511 million more than the projected increase if the 1950-55 average annual net addition to the population would have been maintained. 
Alternatively, following Bongaarts and Bulatao (1999), China's population multiplied by 2.55 times between 1950 and 2015. Increase in population size alone multiplied China's population by 1.58 times, change in the age composition effects on the death rate multiplied the population by 1.71 times, change in the age composition effects on the birth rate multiplied the population by 1.18 times, the decrease in mortality multiplied the population by 2.12 times, and the decrease in fertility multiplied the population by 0.38 times. Thus, the momentum built in China's population stock multiplied China's population by almost 3.20 times, whereas the decrease in fertility and mortality multiplied the population by 0.80 times. India's population multiplied by almost 3.5 times during the period in question. The increase in population size multiplied the population by 1.64 times, change in the age structure effects on the death rate multiplied the population by 1.37 times, change in the age structure effects on the birth rate multiplied the population by 1.10 times, the decrease in mortality multiplied the population by 1.77 times, and the decrease in fertility multiplied the population by 0.80 times, so that the momentum built in the population stock multiplied the population by 2.47 times while the decrease in fertility and mortality multiplied the population by 1.42 times.

\section{$7 \quad$ Changes in the age composition}

Population transition has also resulted in significant changes in the age composition of the population of the two countries. The ratio of the working age to the non-working age population decreased in both countries until 1965 (Table 5; Fig. 7). After 1970, this ratio increased in China until 2010, with more than 90 percent of the increase confined to the periods 1975-85 and 1995-2005. The increase in this ratio from 1965 to 2010 was, however, not uniform, as the ratio almost stagnated between 1990 and 1995. In India, on the other hand, the ratio of the working age population to the non-working age population has increased slowly but consistently after an all-time low in 1965.

As the result of the differential rate of growth of the working age and the nonworking age population, the difference between the growth rate of the working age population and the non-working age population was negative in both countries in the periods 1950-55 and 1960-65 (Fig. 8). The difference in the growth rates of the working age population and the non-working age population in China was exceptionally large during 1980-85, and during 2000-05 as the result of both the increase in the working age population and the decrease in the young population. Between 1980 and 1985, China's population aged less than 15 years decreased by around 28 million, whereas the decrease between 2000 and 2005 was 56 million. At the same time, the working age population increased by around 94 million between 1980 and 1985 and by around 78 million between 2000 and 2005. As the result, the potential support ratio increased from 1.458 in 1980 to 1.778 in 1985 and from 2.153 in 2000 to 2.626 in 2005. However, this ratio decreased from 2.987 in 2010 to 2.734 in 2015 due to a rapid increase in the old-age population by around 21 million. The young popu- 


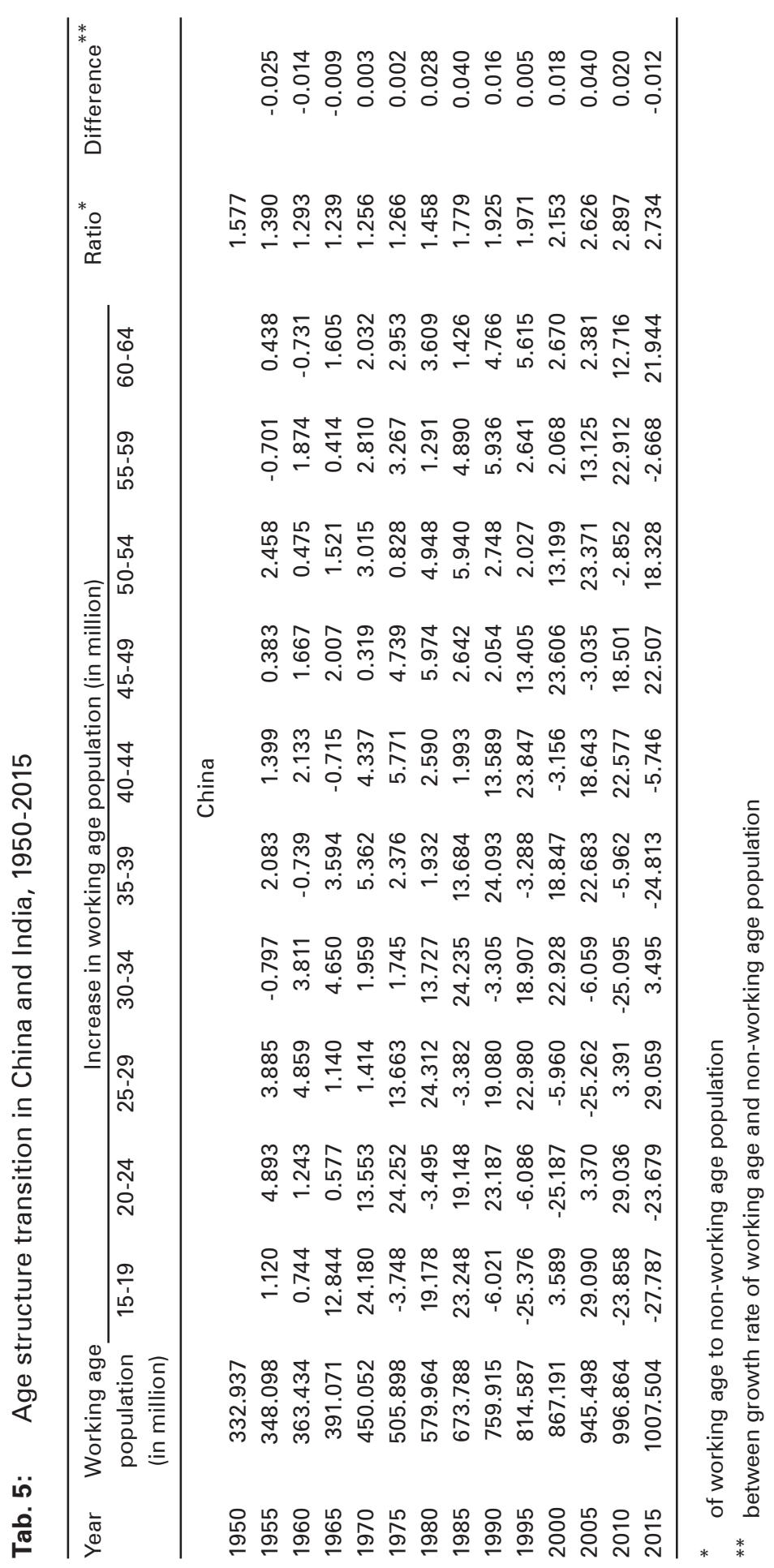




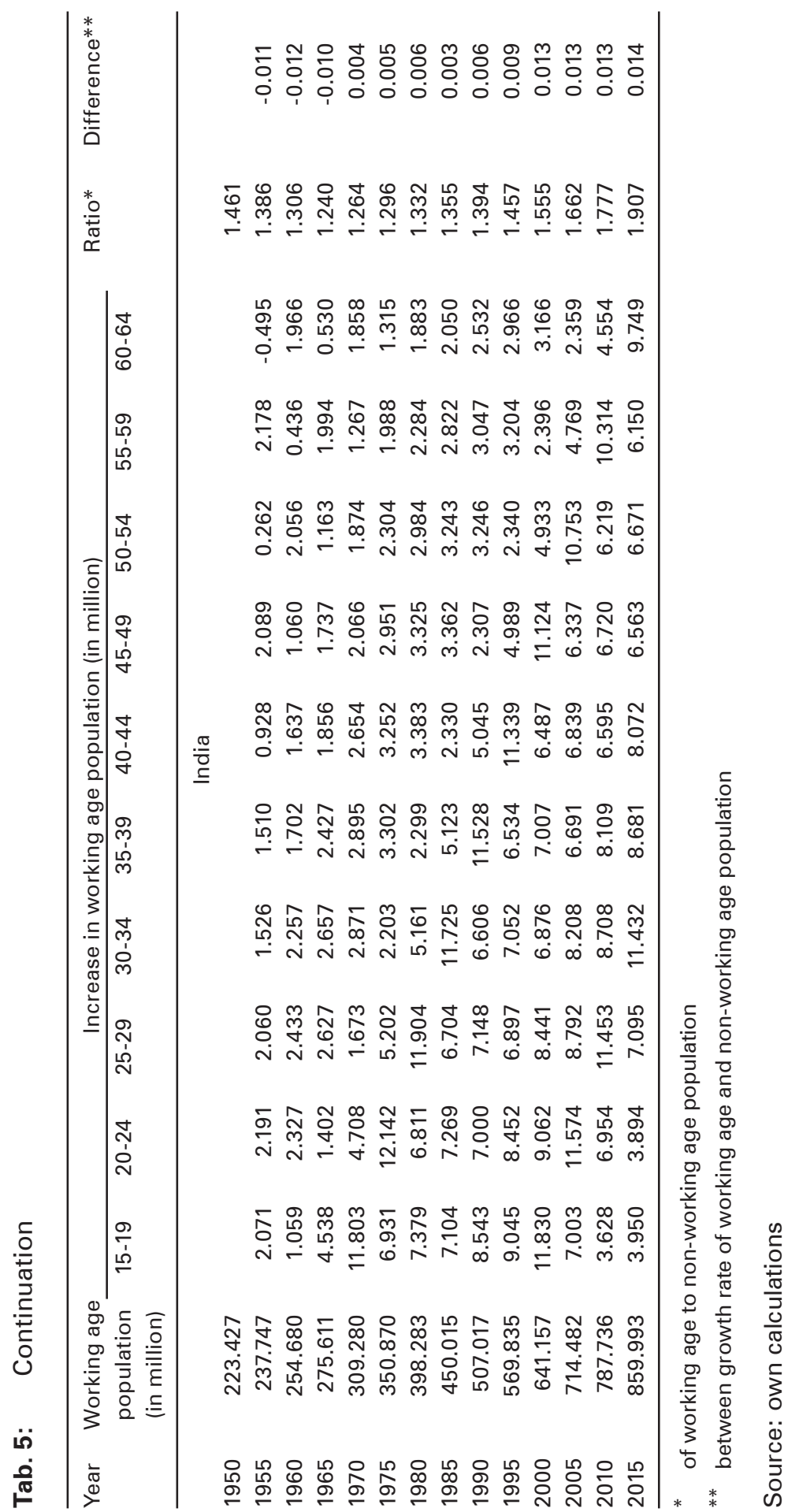


Fig. 7: Demographic dividend (ratio of working age population to non-working age population) in China and India, 1950-2015

Demographic dividend

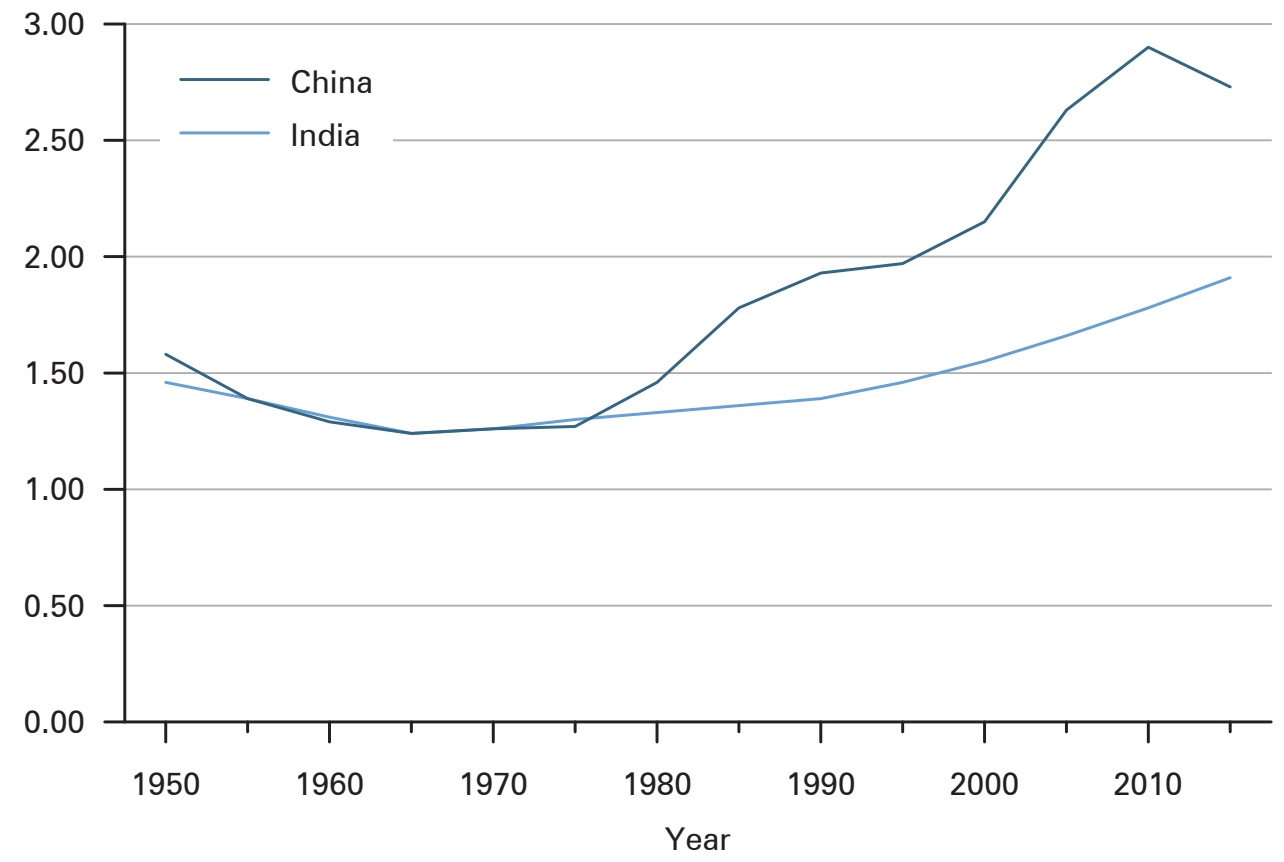

Source: own calculations

lation in the country also increased - albeit marginally - during this period whereas the working age population increased by just about 10 million.

The increase in the working age population in China has however not been distributed evenly across all working ages. Almost 25 percent of the increase in the working age population between 1980 and 1985 was confined to the age group $15-19$ years and another 20 percent to the age group 20-24 years. A rapid increase in the population aged 15-19 years between 1980 and 1985 may be attributed to the increase in the population aged 0-4 years between 1965 and 1970 while the increase in the population aged 20-24 years may be attributed to the increase in the population aged 0-4 years between 1960 and 1965. The increase in the population aged 0-4 years between 1960 and 1965 is attributed primarily to the increase in fertility. While the increase in the population aged 0-4 years between 1965 and 1970 may be attributed primarily to the decrease in mortality, although fertility also increased - albeit marginally - during this period. Similarly, more than 37 percent of the increase in the working age population between 2000 and 2005 may be attributed to the increase in the population aged 0-4 years between 1985 and 1990 as the result of the increase in fertility during this period. This shows that the increase in fertility between 1960 and 1965 and between 1985 and 1990 and the decrease in mortality between 1965 and 1970 contributed significantly to the rapid increase in the po- 
Fig. 8: Demographic dividend (difference between the growth of working age population and growth rate of non-working age population) in China and India, 1950-55 through 2010-15

Demographic dividend

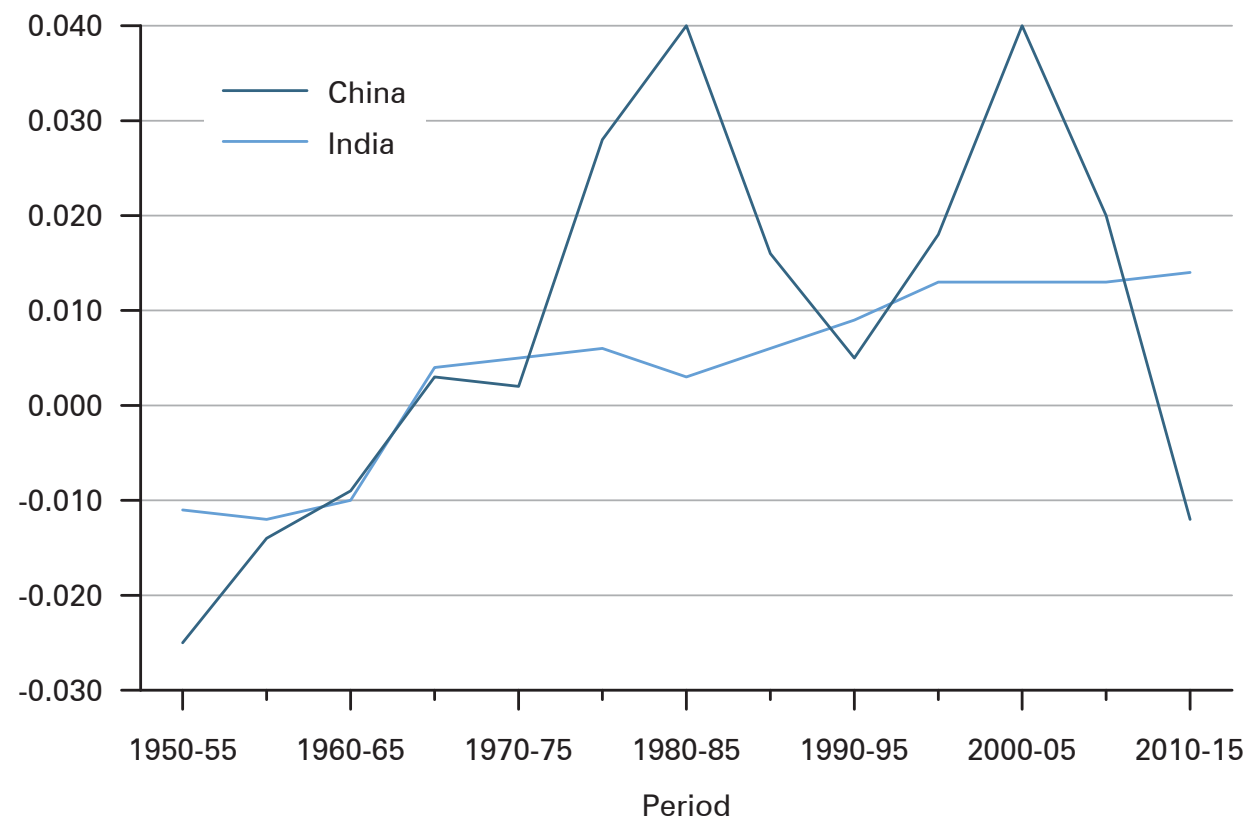

Source: own calculations

tential support ratio in China between 1975 and 1980 and between 2000 and 2005, yielding a very large demographic dividend. However, the demographic window of opportunity in China appears to have closed now as the working age population grew slower than the non-working age population between 2010 and 2015 primarily because of the rapid increase in the old age population, (65 years and above). The working age population in China increased by less than 11 million between 2010 and 2015, compared to an increase by over 24 million in the non-working age population. More than 85 percent of the increase in the non-working age population in this time period is attributed to the increase in the old population from about 111 million in 2010 to more than 131 million in 2015.

In India, the transition in the age composition of the population has been more tempered because both transition in fertility and transition in mortality were slow and fertility never increased meaning the population aged 0-4 years never increased. The potential support ratio in India was higher than that in China from 1960 to 1975. Similarly, the difference between the growth rate of working age and nonworking age populations in India was smaller than that in China - particularly during the periods 1980-85 and 2000-05. Therefore, the demographic dividend in India does not have a telling impact on India's economic growth. However, unlike China, the difference between the growth rate of working and non-working age popula- 
tions continues to increase in India, which implies that the demographic window of opportunity will continue in the near future. It may therefore be postulated that the demographic dividend in India is likely to enfold its potential.

\section{Discussion: Population transition in China and India compared}

Population transition is implicit in the process of social and economic development. The experience of the European countries suggests that as social and economic development advances, death rate decreases, and so do birth rate - usually after a time lag. Therefore, the natural population growth rate first increases and then decreases. The time lag between the onset of the decrease in the death rate and the onset of the decrease in the birth rate determines the increase in the population size and the change in the population age composition, which have economic implications. Although, it is difficult to ascertain the "normal" pace of transition, yet, the pace of population transition can be accelerated through explicit birth rate reduction policies as social and economic development induces a decrease in the death rate.

In line with the above arguments, both China and India made specific efforts to accelerate the pace of population transition. Today, China can claim to have been successful in these efforts, while India's results have been mixed. Population transition in China has been unique in its pace, as its population moved from the state of high fertility and high mortality to a state of low fertility and low mortality in roughly 50 years. There are only two countries - Cuba and Iran - where the pace of population transition matches with that of China (Madsen 2012). The rapid population transition in China has been the subject of intensive research, primarily in the context of the dramatic decrease in fertility attributed to very "strong" family planning efforts (Bongaarts/Greenlagh 1985; Mauldin 1982; Chen 1984; Coale 1984; Wolf 1986; Poston/Gu 1987; Whyte/Gu 1987; Lavely/Freedman 1990). Population transition in India has not been the subject of such intensive research, as it has been far slower. Nonetheless, there are studies that have analysed fertility transition in some parts of India where higher than average decrease in fertility has been observed (Caldwell et al. 1982; Zacharia 1984; Rao et al. 1986; Bhat/Rajan 1990). There are also studies which have compared fertility transition in the two countries (Chaurasia 1999; Kulkarni/ Rani 1995). Mason (1997) has argued that studying fertility transition in isolation from mortality transition is a flawed approach - without mortality transition, fertility transition is highly unlikely. Hirschman (1994) has also argued against the singleminded focus on fertility transition in explaining population transition. There are, however, few studies that have attempted to explain population transition by taking into account transition in both fertility and mortality, and the associated change in population age composition (Chaurasia 2007).

The population transition in China can be divided into four distinct phases. Between 1950-55 and 1955-60, it was primarily the result of the decrease in fertility, whereas the reversal between 1955-60 and 1965-70 was the result of a rapid decrease in mortality, although fertility also increased during this period. From 1965- 
70 to $1995-2000$, population transition in China was dictated largely by changes in fertility, irrespective of whether the natural population growth rate decreased or increased. Since the period 1995-2000, population transition in China has been driven primarily by the changes in age composition, as very low levels of fertility and mortality were achieved by the year 2000 and the intrinsic rate of population growth turned negative, although the natural population growth rate remained positive due to positive age composition effects.

In India, the natural population growth rate began to decrease only after 1985 due to an accelerated decrease in fertility and a deceleration in the decrease in mortality. Chaurasia (2010) has also observed that mortality transition in India has slowed down, particularly after 1980. The slow mortality transition in India may also be judged from the fact that between 1990 and 2015, the under-five mortality rate in India decreased by only about 62 percent, compared to an almost 80 percent decrease in China (United Nations Children's Fund 2015). Had the pace of mortality transition in India not decelerated after 1980, population transition would have been even slower. The slow mortality transition in India also appears to be a reason behind the slow fertility transition.

An important distinction between population transition in the two countries is the timing of transition in fertility and mortality. Rapid fertility transition in China after 1970 was preceded by rapid mortality transition in the 1960s. The very low level of mortality achieved in China around 1970 appears to have served as the necessary impetus for the rapid decrease in fertility in the 1970s, as argued by Mason (1997). In India, the decrease in mortality has never been substantial enough to act as a catalyst for accelerating the decrease in fertility.

The achievement of replacement fertility is widely used as an indicator of fertility transition. However, Espenshade et al. (2003) have shown that the key determinant of cross-national variation in replacement fertility is the difference in mortality. In countries where mortality is high, replacement fertility is much higher than the widely assumed global average of 2.1 lifetime births per woman, which means that the proportion of young population remains large, and the demographic dividend therefore small. Even today, accelerating mortality transition remains a major public health challenge to India.

The typical nature of population transition in China has led to a pronounced demographic dividend. This has not been the case in India. However, the demographic dividend in China was basically confined to two short periods 1975-85 and 2000-05. If these two time periods are excluded, then China's demographic dividend has been very similar to that in India. The demographic window of opportunity in China is now closed, and the country is likely to enter a long period of decrease in labour supply and a rapid increase in the elderly population which will be difficult to be reversed quickly (Wang/Mason 2007). India has not yet benefitted from the demographic dividend, but the window of opportunity is widening, which suggests that much of the country's potential demographic dividend lies ahead (Golley/Tyers 2012).

Population transition in China appears to be sensitive to the country's population and development policies, while this does not seem to be the case in India. The de- 
crease in the natural population growth rate in China in the 1950s may be attributed to the first birth planning campaign (1956-58), whereas the increase in the natural population growth rate (1955-65) appears to be attributed to the Great Leap Forward programme (1958-62), which focused on the decentralisation of the industry and collectivisation of agriculture (Chen/Kols 1982). Although there was no change in the official policy towards birth planning, yet the Malthusian perspective was denounced throughout the Great Leap Forward (Chen 1976). The increase in the natural population growth rate during this period would have been even more rapid had the mortality not nearly stagnated because of a large number of famine deaths associated with the programme (Ashton et al. 1984; Yang 2008). There was virtually no increase in the expectation of life at birth in China between 1955-60 and 1960-65. Similarly, the increase in the natural population growth rate between 1960-65 and 1965-70 may be attributed to a very rapid decrease in mortality to pre-leap levels as the result of the new economic policy (1960-65) which restored the downward trend in mortality that had begun in 1955 (Coale 1984). On the other hand, very rapid population transition between 1965 and 1980 may be attributed to the third birth planning campaign, popularly known as the "Later, Longer, Fewer" campaign (197179), which focused on later marriage, longer spacing between births, and fewer children (Chen 1972). It was explicitly stated at the policy level that modernisation of agriculture, industry, defence and science would be contingent upon achieving zero population growth in the near future, and the target of reducing the natural population growth rate to 10 per 1000 by 1980 was set (Hua 1978). However, the transition reversed during 1985-90, despite the launch of the One Child Policy in 1979, largely because of the increase in fertility which has been attributed to women born during the baby boom period of 1960s and the inability of the birth planning efforts to control unplanned births (Yang 1991).

In India, population and development policies have had little visible impact on population transition, although the commitment to reducing fertility and curtailing population growth has explicitly been stated in all Five-year Development Plans, and population and health policies of the country since independence. Nonetheless, the country has always been an under-achiever in terms of demographic goals and targets set at the policy level. For example, the target of achieving a crude birth rate of 25 live births per 1,000 population by the year 1972 was set in 1962, but could be achieved only in 2002 - 30 years later (Chaurasia/Gulati 2008). Similarly, the 2000 target of achieving replacement fertility by 2010 is yet to be achieved. The observed insensitiveness of population transition to official population and development policies appears to be a major reason behind the slow population transition in India.

In both countries, the momentum for growth intrinsic to the population stock - size and age composition - has increasingly become important in determining population growth. In China, the intrinsic rate of population growth - the difference between the age independent birth and death rates - turned negative after 2000, but the age structure effects on birth and death rates kept the natural population growth rate positive. In India, the relative importance of the age component in deciding the natural population growth rate has increased from less than 20 percent during 1950-55 to almost 80 percent during 2010-15. This observation has impor- 
tant implications for population and development policies. The age component of the natural population growth rate reflects the age composition effects on birth and death rates, which are essentially arithmetic accounting effects. They do not affect the level of fertility and mortality, but rather influence birth and death rates. They also reflect the level of fertility and mortality in the past.

According to the medium variant of the 2015 revision of UN population projections, India's population is projected to increase up to the year 2068, when it will most likely cross 1.754 billion (United Nations 2015a). The increase in India's population will account for more than 414 million, or roughly 16 percent, of the 2.637 billion projected increase in the world population between 2015 and 2050. By contrast, China's population is projected to start decreasing after 2028 and is projected to decrease to 1 billion by the turn of the century, so that around 2100, India's population will be almost 60 percent larger than that of China.

Both countries require an appropriate policy response to the current state of population transition, so that the change in the population stock in the coming years remains in tune with sustainable development which is a development that meets the needs of the present without compromising the ability of future generations to meet their own needs. Sustainable development has two key concepts, the concept of needs and the idea of limitations imposed by the state of technology and social organisation on the ability of the environment to meet present and future needs (United Nations 1987). Sustainability requires living with the regenerative capacity of biosphere (Wackernagel et al. 2002). The 2030 agenda for sustainable development adopted by the United Nations General Assembly defines sustainable development in terms of the balance between economic growth, social inclusion and environmental protection (United Nations 2015b). Although, population is not explicitly mentioned in the 2030 sustainable development agenda, yet it matters greatly in achieving the sustainable development goals. Population dynamics affect not only the development objectives but also have a strong impact on social, economic and environmental dimensions of sustainable development. It is argued that efforts to promote sustainable development without addressing population dynamics will continue to fail (United Nations Population Fund 2012). China has already responded to its current state of population transition by amending its Population and Family Planning Law of 2001. The article 18 of the 2001 Law was amended in 2015 and now provides that the state advocates that every married couple have two children and that more children may be allowed where requirements specified by law and regulations are met. The new law also does not encourage late marriage and late childbearing. The law, popularly known as the universal two-child policy, is a policy response to the state of population transition in the country and an effort to maintain the demographic balance necessary for sustainable development. This policy-level initiative has been deemed timely, necessary and inevitable for social and economic development of the country (Zheng 2016). Others, however, have expressed concerns about the effectiveness of the changes introduced, as the effect of the new policy on the shrinking work force and rapid population ageing will not be evident for another two decades (Wang et al. 2016; Padmadas 2017; Zeng/ Hesketh 2016). By contrast, India remains largely insensitive to the current state of 
population transition, even at the policy level. It continues to uphold the National Population Policy 2000 despite the fact that the policy goal of achieving replacement fertility by 2010 could not be reached and the medium-term goal of stabilising population growth by 2040 appears only a distant possibility. The total fertility rate in India still continues to hover around 2.2-2.3 life time births per woman of reproductive age (Government of India 2016, 2017a), but the fertility of married women remains very high at 4.6 life time births per married women of reproductive age (Government of India 2016). At the same time, the expectation of life at birth remains well below 70 years (Government of India 2016). Recently, the Government of India has announced a new health policy which aims at reducing the total fertility rate to replacement level and increasing the expectation of life at birth to 70 years by the year 2025 - about 25-30 years later than China (Government of India 2017b). On the other hand, in response to a question in the Parliament in 2015, the Health Minister of India argued that the 2000 National Population Policy was uniformly applicable to the entire population, irrespective of religious or community affiliations and that there was no proposal under consideration by the government to formulate new population policy (Government of India 2015).

\section{Conclusion}

The main objective of this paper was to show how changes in different demographic drivers contributed to population transition in China and India, the world's two most populous countries, and to identify the demographic causes which have been responsible for the different population transition path followed by the two countries. Our analysis shows that changes in both the intrinsic and the age component of population growth have contributed to population transition in both countries. The analysis also suggests that the relative contribution of the age component of the natural population growth is becoming more dominant in deciding the natural population growth rate than the intrinsic component. This observation is important from the policy perspective. The momentum of growth generated by the change in population age composition cannot be eliminated. It can, at best, be delayed by increasing the age at first birth and extending the interval between successive births (Andreev et al. 2013; Bongaarts 1994).

From the policy perspective, the present analysis suggests that priorities for addressing population trends should partly be informed by the relative contribution of different demographic drivers of population growth. Since the relative contribution of different demographic drivers on population growth is different at different stages of population transition, it is imperative that formulation and adoption of population policy should be conducted in a dynamic manner, and should be adapted as the population transition advances. 


\section{References}

Adlakha, Arjun; Banister, Judith 1995: Demographic perspectives on China and India. In: Journal of Biosocial Science 27,2: 163-178 [doi: 10.1017/S0021932000022677].

Andreev, Kirill; Kantorová, Vladimíra; Bongaarts, John 2013: Demographic components of future population growth. Technical Paper No. 2013/3. New York: United Nations, Population Division.

Ashton, Basil et al. 1984: Famine in China. In: Population and Development Review 10,4: 613-645 [doi: 10.2307/1973284].

Bloom, David E. 2011: Population dynamics in India and implications for economic growth. Working Paper No. 65. Harvard University, Program on the Global Demography of Ageing, PGDA

Bloom David E.; Williamson, Jeffrey G. 1998: Demographic transitions and economic miracles in emerging Asia. In: World Bank Economic Review 12,3: 419-456.

Bloom, David E.; Canning, David 2005: Global demographic change: dimensions and economic significance. In: Global Demographic Change: Economic Impacts and Policy Challenges. Federal Reserve Bank of Kansas City.

Bloom, David E.; Canning, David 2004: Global demographic change: dimensions and economic significance. Working Paper No. 10817. National Bureau of Economic Research [doi: 10.3386/w10817].

Bloom, David E.; Canning, David; Malaney, Pia N. 2000: Population dynamics and economic growth in Asia. In: Population and Development Review 26 (Supplement) Population and Economic Change in East Asia: 257-290.

Bloom, David E.; Canning, David; Sevilla, Jaypee 2003: The Demographic Dividend: A New Perspective on the Economic Consequences of Population Change. MR-1274. Santa Monica: RAND.

Bloom, David E. et al. 2006: Demographic Change and Economic Growth: Comparing China and India. Boston: Harvard University, Harvard School of Public Health.

Bhat, PN Mari; Rajan, S. Irudaya 1990: Demographic transition in Kerala revisited. In: Economic and Political Weekly 25,35-36: 1957-1980.

Bongaarts, John; Greenlagh, Susan 1985: An alternative to one-child policy in China. In: Population and Development Review 11,4: 585-617.

Bongaarts, John 1994: Population policy options in the developing world. In: Science 263: 27.

Bongaarts, John 2009: Human population growth and the demographic transition. In: Philosophical Transactions of the Royal Society B: Biological Sciences 364,1532: 2985-2990 [doi: 10.1098/rstb.2009.0137].

Bongaarts, John; Bulatao, Rodolfo A. 1999: Completing the demographic transition. In: Population and Development Review 25,3: 515-529 [doi: 10.1111/j.17284457.1999.00515.x].

Bourgeois-Pichat, Jean; Taleb, Si-Ahmed 1970: Un taux d'accroissement nul pour les pays en voie dédeveloppement en I'an 2000. Réve or réalité? In: Population 25,5: 951 974.

Cai, Feng; Wang, Dewen 2005: Demographic transition: implications for growth. In: Garnaut, Ross; Song, Ligang (Eds.): The China Boom and its Discontents. Canberra: Asia-Pacific Press. 
Caldwell, John C.; Reddy, PH.; Caldwell, Pat 1982: The causes of demographic change in rural south Asia: a micro approach. In: Population and Development Review 8,4: 689-727 [doi: 10.2307/1972469].

Chaurasia, Alok R. 1999: A comparative analysis of fertility transition in China and India. In: Chaurasia, Alok Ranjan (Ed.): Population and Development. The Indian Perspective. Datia, 'Shyam' Institute and Universal Publishers.

Chaurasia, Alok R. 2007: A comparative analysis of population transition in India and China. Working Paper No. E/286/2007. Delhi: Institute of Economic growth.

Chaurasia, Alok R. 2010: Mortality transition in India: 1970-2005. In: Asian Population Studies 6,1: 47-68 [doi: 10.1080/17441731003603421].

Chaurasia, Alok R.; Gulati, Subhash C. 2008: India: The State of Population 2007. New Delhi: National Population Commission/Oxford University Press.

Chen, Pi-chao; Kols, Adrienne 1982: Population and birth planning in the People's Republic of China. In: Population Reports J,25. Baltimore: John Hopkins University.

Chen, Pi-chao 1972: China's population program at the grass roots level. In: Studies in Family Planning 4,8: 219-227.

Chen, Pi-chao 1976: Population and Health Policy in People's Republic of China. Interdisciplinary Communication Program Occasional Monograph No. 9. Washington DC: Smithsonian Institute.

Chen, Shengli 1984: Fertility of women during 42 years period from 1940-1981. In China Population Centre Analysis of China's National One-per-thousand Fertility Sampling Survey. Beijing: China Population Information Centre.

Chesnais, Jean-Claud 1979: L'effet multiplicatif de la transition démographique. In: Population 36,6: 1138-1144 [doi: 10.2307/1531438].

Chesnais, Jean-Claud 1986: La transition démographique: Etapes, formes, implications économiques. Cahier INED No. 113. Paris: Presses Universitaires de France.

Chesnais, Jean-Claud 1990: Demographic transition patterns and their impact on the age structure. In: Population and Development Review 16,2: 327-336 [doi: 10.2307/1971593].

Choudhry, Misbah T.; Elhorst, J. Paul 2010: Demographic transition and economic growth in China, India and Pakistan. In: Economic Systems 34: 218-236 [doi: 10.1016/j. ecosys.2010.02.001].

Coale, Ansley J. 1983: Population trends in China and India (A review). In: Proceedings of National Academy of Sciences USA 80: 1757-1763.

Coale, Ansley J. 1984: Rapid Population Change in China 1952-1982. Washington DC: National Academies Press [doi: 10.17226/61].

Da Vanzo, Julie; Dogo, Harun; Grammich, Clifford A. 2011: Demographic trends, policy influences, and economic effects in China and India through 2025. Working Paper WR849. Santa Monica: RAND Corporation, National Security Research Division.

Desai, Meghnad 2003: India and China: an essay in comparative political economy. Paper presented at IMF Conference: A Tale of Two Giants: India's and China's Experience with Reform and Growth. New Delhi: National Council of Applied Economic Research.

Espenshade, Thomas J. 1975: The stable decomposition of the rate of natural increase. In: Theoretical Population Biology 8: 97-115.

Espenshade, Thomas J.; Guzman, Juan C.; Westoff, Charles F. 2003: The surprising global variation in replacement fertility. In: Population Research and Policy Review 22,5-6: 575-583 [doi: 10.1023/B:POPU.0000020882.29684.8e]. 
Espenshade, Thomas J.; Tannen, Jonathan B.C. 2015: Population dynamics. Momentum of population growth. In: Wright, James D. (Ed.): International Encyclopedia of Social and Behavioral Sciences. Second Edition, Volume 18.

Frejka, Tomas 1973: The Future of Population Growth: Alternative Paths to Equilibrium. New York: John Wiley.

Frejka, Tomas 1981: Longterm prospects for world population growth. In: Population and Development Review 7,3: 489-511.

Golley, Jane; Tyers, Rod 2012: Demographic dividends, dependencies and economic growth in China and India. Discussion Paper 12.03. University of Western Australia Business School.

Government of India 2000: National Population Policy 2000. New Delhi: Ministry of Health and Family Welfare.

Government of India 2013: Compendium of Fertility and Mortality Indicators 1970-2013. New Delhi: Registrar General and Census Commissioner of India.

Government of India 2015: National Population Policy. New Delhi: Ministry of Health and Family Welfare. Press Information Bureau.

Government of India 2016: Sample Registration System Statistical Report 2015. New Delhi: Registrar General and Census Commissioner of India.

Government of India 2017a: National Family Health Survey - 4. 2015-16. India Fact Sheet. Mumbai: International Institute for Population Sciences.

Government of India 2017b: National Health Policy 2017. New Delhi: Ministry of Health and Family Welfare.

Hirschman, Charles 1994: Why fertility changes. In: Annual Review of Sociology 20: 203-233.

Horiuchi, Shiro 1991: Measurement and analysis of cohort size variations. In: Population Bulletin of the United Nations 30: 106-124.

Horiuchi, Shiro 1992: Stagnation in the decline of the world population growth rate during the 1980s. In: Science 257: 761-765 [doi: 10.1126/science.1496396].

Horiuchi, Shiro 1993: The world population growth rate: why declines stalled in the 1980s. In: Population Today 21,6: 69.

Horiuchi, Shiro 1995: The cohort approach to population growth: A retrospective decomposition of growth rates for Sweden. In: Population Studies 49: 147-163 [doi: 10.1080/0032472031000148296].

Hua, Guofeng 1978: United together and struggle for constructing a socialist modernized nation. In: Red Flag 3: 3-21.

Joe, William; Dash, Atish K.; Agrawal, Pradeep 2015: Demographic transition, savings and economic growth in China and India. Working Paper No. 351. Delhi: Institute of Economic Growth.

Kandiah, Vasanth; Horiuchi, Shiro 1995: Recent trends and prospects in world population growth. In: Population Bulletin of the United Nations 39: 133-146.

Keck, Zachary 2013: China's demographic dividend could end by 2015. In: The Diplomat July 23.

Kelkar, Vijay 2004: India: on the growth turnpike. Narayanan Oration Speech. Canberra: Australian National University.

Keyfitz, Nathan 1971: On the momentum of population growth. In: Demography 8,1: 71-80. 
Kitagawa, Everlin M. 1955: Components of difference between two rates. In: Journal of the American Statistical Association 50,272: 1168-1194 [doi: 10.2307/2281213].

Kulkarni, Purushottam M.; Rani S. 1995: Recent fertility declines in China and India: a comparative view. In: Asia-Pacific Population Journal 10,4: 53-74.

Lavely, William; Freedman, Ronald 1990: The origins of Chinese fertility decline. In: Demography 27,3: 357-367.

Madsen, Elizabeth L. 2012: Iran: A seemingly unlikely setting for world's fastest demographic transition. In: New Security Beat January 11.

Mason, Andrew 2007: Demographic transitions and demographic dividends in developed and developing countries. United Nations Expert Group Meeting on Social and Economic Implications of Changing Population Age Structures. New York: United Nations, Department of Economic and Social Affairs, Population Division.

Mason, Karen O. 1997: Explaining fertility transitions. In: Demography 34,4: 443-457.

Mauldin, W. Parker 1982: The determinants of fertility decline in developing countries. An overview of available empirical evidence. In: International Family Planning Perspective 8,3: 116-121.

Notestein, Frank W. 1945: Population: the long view. In: Schultz, Theodore W. (Ed.): Food for the World. Chicago: University of Chicago Press: 36-57.

Notestein, Frank W. 1960: Mortality, fertility, the size-age distribution and the growth rate. In: Demographic and Economic Change in Developed Countries. National Bureau of Economic Research. Columbia University Press: 261-284.

Padmadas, Sabu S. 2017: Two-child policy in China. Rhetoric versus reality. In: Annals of Human Biology 44,2: 1-2 [doi: 10.1080/03014460.2016.1177113].

Poston, Dudley L.; Gu, Baochang 1987: Socio-economic development, family planning and fertility in China. In: Demography 24: 531-555.

Preston, Samuel H.; Guillot, Michel 1997: Population dynamics in an age of declining fertility. In: Genus 53,3-4: 15-31.

Preston, Samuel H.; Heuveline, Patrick; Guillot, Michel 2001: Demography. Measuring and Modelling Population Processes. Oxford: Blackwell Publishers: 136.

Roubanis, Ilia 2016: China's demographic transition has come to an end. In: Government Affairs January 25.

Rao, N. Baskara; Kulkarni, Purushottam M.; Rayappa, P. Hanumantha 1986: Determinants of Fertility Decline. A Study of Rural Karnataka. New Delhi: South Asian Publishers.

Roy, S. Guha 1993: Demography of China and India: a comparative study. In: International Union for the Scientific Study of Population (IUSSP). International Population Conference. Liege, Belgium: IUSSP: 173-186.

Schmidt, Johannes D. 2011: India and China in comparative perspective - emerging Asian and global powers. Paper presented at Madras Institute of Development Economics, Chennai.

Schoen, Robert 2002: Mathematical models in demography and actuarial mathematics. Working Paper No. 0207. University Park, Pennsylvania State University, Population Research Institute.

Schoen, Robert; Kim, Young J. 1991: Movement toward stability as a fundamental principle of population dynamics. In: Demography 28,3: 455-466 [doi: 10.2307/2061467]. 
Smith, Stanley K.; Ahmed, Bashir 1990: A demographic analysis of the population growth of the states, 1950-1980. In: Journal of Regional Science 30,2: 209-227 [doi: 10.1111/j.1467-9787.1990.tb00093.x].

United Nations 1987: Report of the World Commission on Environment and Development. Our Common Future. New York: United Nations.

United Nations 2006: World Population Prospects: The 2004 Revision. Volume III. AnaIytical Report. New York: United Nations, Department of Economic and Social Affairs, Population Division.

United Nations 2015a: World Population Prospects: The 2015 Revision. DVD Edition. New York: United Nations, Department of Economic and Social Affairs, Population Division.

United Nations 2015b: Transforming Our World: The 2030 Agenda for Sustainable Development. New York: United Nations.

United Nations 2017: World Population Prospects: The 2017 Revision. DVD Edition. New York: United Nations, Department of Economic and Social Affairs, Population Division.

United Nations Children's Fund 2015: Levels and Trends in Child Mortality. Report 2015. Estimates Developed by United Nations Interagency Group for Child Mortality Estimation. New York: United Nations Children's Fund.

United Nations Population Fund 2012: Population Matters for Sustainable Development. New York: United Nations Population Fund.

Vallin, Jacques 2006: Europe's demographic transition 1740-1940. In: Caselli, Graziella; Vallin, Jacques; Wunsch, Guillaume (Eds): Demography: Analysis and Synthesis. New York: Academic Press.

Vermeer, Eduard B. 2006: Demographic dimensions of China's development. In: Demeny, Paul; McNicoll, Geoffrey (Eds.): The Political Economy of Global Population Change, 1950-2050. Supplement to Population and Development Review 32. New York: Population Council.

Wackernagel, Mathis et al. 2002: Tracking the ecological overshoot of the human economy. In: Proceedings of National Academy of Sciences 99,14: 9266-9271 [doi: 10.1073/ pnas.142033699].

Wang, Feng 2010: China's population destiny: The looming crisis. New York: Brookings Institution.

Wang, Feng; Mason, Andrew 2007: Demographic dividend and prospects of economic development in China. In: United Nations Expert Group Meeting on Social and Economic Implications of Changing Population Age Structures. New York, United Nations, Department of Economic and Social Affairs, Population Division.

Wang, Feng; Gu, Baochang; Cai, Yong 2016: The end of China's one child policy. In: Studies in Family Planning 47,1: 83-86 [doi: 10.1111/j.1728-4465.2016.00052.x].

White, Michael J.; Subedi, Inku 2008: The demography of China and India: Effects on migration to high income countries through 2030. Washington DC: Migration Policy Institute.

Williamson, Jeffrey G. 1977: Growth, distribution and demography: some lessons from history. Working Paper No. 6244. Cambridge MA: National Bureau of Economic Research [doi: 10.3386/w6244].

Whyte, Martin K.; Gu, Shengzu 1987: Popular response to China's fertility transition. In: Population and Development Review 13,3: 471-493. 
Wolf, Arthur P. 1986: The pre-eminent role of government intervention in China's family revolution. In: Population and Development Review 12,1: 101-116.

Wolf, Charles Jr. et al. 2011: China and India, 2025 A Comparative Assessment. Santa Monica: RAND Corporation.

Yang, Dennis T. 2008: China's agricultural crisis and famine of 1959-61. A survey and comparison to Soviet famines. In: Comparative Economic Studies 50,1: 1-29.

Yang, S. 1991: An analysis of the population growth in the Seventh Five-year Plan period. In: China Population Today 8,3: 11-12.

Zacharia, K.C. 1984: The Anomaly of Fertility Decline in Kerala State: A Field Investigation. Staff Working Paper No. 700. Washington DC: The World Bank.

Zeng, Yi; Hesketh, Therese 2016: The effects of China's universal two child policy. In: The Lancet 388,10054: 1930-1938.

Zheng, Bingwen 2016: Population ageing and the impacts of the universal two child policy on China's socio-economy. In: Economic and Political Studies 4,4: Special Issue: Ageing and its Implications: China and the World [doi: 10.1080/20954816.2016.1251136].

Prof. Dr. Aalok Ranjan Chaurasia ( $₫)$. Shyam Institute. India.

E-mail: aranjan@shyaminstitute.in

URL: www.shyaminstitute.in 


\section{Comparative Population Studies}

wWW.comparativepopulationstudies.de

ISSN: 1869-8980 (Print) - 1869-8999 (Internet)

\section{Published by}

Prof. Dr. Norbert F. Schneider

Federal Institute for Population Research D-65180 Wiesbaden / Germany

\section{(cc) BY-SA}

2017

\section{Managing Editor}

Frank Swiaczny

\section{Assistant Managing Editor}

Katrin Schiefer

\section{Copy Editor}

(Selected Articles in German)

Dr. Evelyn Grünheid

\section{Layout}

Beatriz Feiler-Fuchs

E-mail: cpos@bib.bund.de

\section{Scientific Advisory Board}

Paul Gans (Mannheim)

Karsten Hank (Cologne)

Johannes Huinink (Bremen)

Michaela Kreyenfeld (Rostock)

Marc Luy (Vienna)

Notburga Ott (Bochum)

Peter Preisendörfer (Mainz)

Nikola Sander (Groningen)

Zsolt Spéder (Budapest)

\section{Board of Reviewers}

Martin Abraham (Erlangen)

Laura Bernardi (Lausanne)

Hansjörg Bucher (Bonn)

Claudia Diehl (Konstanz)

Andreas Diekmann (Zurich)

Gabriele Doblhammer-Reiter (Rostock)

Jürgen Dorbritz (Wiesbaden)

Anette Eva Fasang (Berlin)

E.-Jürgen Flöthmann (Bielefeld)

Alexia Fürnkranz-Prskawetz (Vienna)

Beat Fux (Salzburg)

Joshua Goldstein (Berkeley)

Sonja Haug (Regensburg)

Hill Kulu (Liverpool)

Aart C. Liefbroer (The Hague)

Kurt Lüscher (Konstanz)

Emma Lundholm (Umeå)

Nadja Milewski (Rostock)

Dimiter Philipov (Vienna)

Roland Rau (Rostock)

Tomáš Sobotka (Vienna)

Jeroen Spijker (Barcelona)

Olivier Thévenon (Paris)

Helga de Valk (Brussels)

Heike Trappe (Rostock)

Michael Wagner (Cologne) 